PontIFícIa UNIVERSIDADE CATÓLICA dO RIO DE JANEIRO

A influência do ambiente físico na percepção do consumidor em relação a lojas de varejo

Rafael Barreiro Bastos Arnaud Fonseca

Trabalho de Conclusão de Curso

Centro de ciências socials - CCS

DEPARTAMENTO de AdMINISTRAÇÃo

Graduação em Administração de Empresas 
Rafael Barreiro Bastos Arnaud Fonseca

A influência do ambiente físico na percepção do consumidor em relação a lojas de varejo

Trabalho de Conclusão de Curso

Trabalho de Conclusão de Curso, apresentado ao programa de graduação em Administração da PUC-Rio como requisito parcial para a obtenção do título de graduação em Administração.

Orientador: André Lacombe Penna da Rocha

Rio de Janeiro

Novembro de 2019. 


\title{
A influência do ambiente físico na percepção do consumidor em relação a lojas de varejo
}

\author{
RAFAEL BARREIRO BASTOS ARNAUD FONSECA
}

André Lacombe Penna da Rocha

\section{RESUMO}

Este trabalho tem como objetivo uma melhor compreensão das características que compõem o ambiente físico das lojas de varejo, sejam elas internas, relativas à ocupação e conservação do espaço, ou externas, referentes aos aspectos construtivos do imóvel, e seu impacto na percepção dos consumidores dentro da cidade do Rio de Janeiro. Devido a subjetividade do problema de estudo, foi utilizado o método de análise hierárquica de Saaty, capaz de gerar uma hierarquia objetiva para decisões subjetivas através de comparações par a par. Os resultados permitiram uma melhor compreensão de formas de possivelmente converter o fluxo de pessoas na região em visitas à loja, gerando uma maior receita de venda e impactando a avaliação do imóvel

\section{Palavras-chave:}

Ambiente físico, Comportamento do consumidor, Marketing de serviços, Método de análise hierárquica, Setor imobiliário, Varejo.

\section{RESUMO}

This research objective is to have a better understanding of the features that composse the physical environment of retail stores, may them be interior, relative to the occupation and conservation of the space, or exterior, referent to constructive aspects of the property, and their impact in the perception of the consumers in the city of Rio de Janeiro. Due to the subjectivity of the problem researched, Saaty's hierarchical analysis method was used, since it's capable of generating an objective hierarchy for subjective decisions through pairwise comparisons. The results granted a better understanding of ways to possibly convert the flow of people in the region into visits to the store, generating a bigger sales revenue and impacting the property appraisal.

\section{Palavras-chave:}

Consumer behavior, Hierarchical analysis method, Physical Environment, Real State, Retail, Service marketing. 


\section{Sumário}

1 . Introdução 1

1.1. Introdução ao tema e problema de estudo 1

1.2. Objetivo Principal 4

1.3. Objetivos Intermediários 5

1.4. Delimitação do Estudo 5

1.5. Justificativa e Relevância do Estudo 6

2. Referencial Teórico $\quad 7$

2.1. Setor Imobiliário 7

2.2. Avaliação Imobiliária 8

2.3. Varejo 8

2.4. Ferramentas de Marketing 9

$\begin{array}{ll}\text { 2.5. Marketing de Serviços } & 10\end{array}$

2.6. Evidências Físicas (Palpabilidade) 12

2.7. Antropologia do Consumo 14

2.8. Comportamento do Consumidor 15

$\begin{array}{ll}\text { 2.9. Influências no Comportamento de Compra } & 17\end{array}$

3. Metodologia da Pesquisa 20

3.1. Método de Análise Hierárquica (MAH) 20

3.2. Composição dos Grupos Focais 23

3.3. Coletas de Dados 24

3.4. Tratamento de Dados 26

3.5. Limitações do Método 29

4 .Pesquisa de Campo 31

4.1. Fase de Pré-Testes 31

4.2. Validação dos Elementos 32

4.3. Comparações dos Elementos 32

4.4. Resultados da Estrutura 38

4.5. Tabelas de Hierarquia 41 
5 . Conclusão

Referências Bibliográficas

46

APÊNDICE A - IMAGENS UTILIZADAS NA PESQUISA

APÊNDICE B - MEMÓRIA DE CÁLCULO 


\section{LISTA DE FIGURAS}

Figura 1 - Expectativas dos índices IPCA, PIB e taxa SELIC para o final de 2019, segundo gestores de fundos consultados pela XP investimentos ...... 2

Figura 2 - Principais motivos para consumo no varejo físico .............................. 4

Figura 3 - Processo de Administração de Marketing...................................... 10

Figura 4 - Continuum de Bens e Serviços ................................................. 11

Figura 5 - Categorias de impacto do ambiente no comportamento ................... 13

Figura 6 - Etapas do processo de decisão de compra .................................... 16

Figura 7 - Modelo contemporâneo de influência de compra ............................ 17

Figura 8 - Fatores que influenciam no comportamento .................................. 19

Figura 9 - Estrutura do Método de Análise Hierárquica ................................. 21

Figura 10 - Estrutura MAH para elaboração da pesquisa ............................... 22

Figura 11- Exemplo de alocação dos pesos relativos na estrutura .................... 27

Figura 12 - Exemplo de fluxo de multiplicação de matrizes prioridade .............. 28

Figura 13 - Exemplo de resultado final ..................................................... 28

Figura 14 - Estrutura de prioridades (consumidores) .................................... 39

Figura 15 - Estrutura de prioridades (mercado) .......................................... 39 


\section{LISTA DE TABELAS}

Tabela 1 - Escala fundamental de Saaty ................................................ 22

Tabela 2 - Exemplo de matriz comparação antes do preenchimento................. 24

Tabela 3 - Exemplo de preenchimento das respostas na matriz comparação .. 25

Tabela 4 - Exemplo de matriz comparação completa ..................................... 25

Tabela 5 - Exemplo de matriz normalizada.............................................. 26

Tabela 6 - Exemplo de média e vetor ......................................................... 26

Tabela 7- Exemplo de matriz prioridade ...................................................... 27

Tabela 8 - Comparações dos subgrupos .................................................... 33

Tabela 9 - Comparações dos critérios no subgrupo externos .......................... 33

Tabela 10 - Comparações dos critérios no subgrupo internos ......................... 34

Tabela 11 - Comparações das características para o critério estética (externo) 35

Tabela 12 - Comparações das características para o critério visibilidade

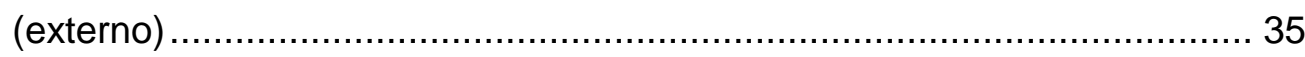

Tabela 13 - Comparações das características para o critério conforto (externo)36 Tabela 14 - Comparações das características para o critério estética (interno) 37 Tabela 15 - Comparações das características para o critério visibilidade (interno)

Tabela 16 - Comparações das características para o critério conforto (interno) 38

Tabela 17 - Resultado Final (consumidores) ............................................. 40

Tabela 18 - Resultado Final (mercado) ...................................................... 40

Tabela 19 - Hierarquia das características do ambiente físico ......................... 41

Tabela 20 - Hierarquia estética............................................................... 42

Tabela 21 - Hierarquia visibilidade .............................................................. 42

Tabela 22 - Hierarquia conforto ............................................................... 43 


\section{Introdução}

\subsection{Introdução ao tema e problema de estudo}

Após alguns anos de recessão a economia brasileira vem mostrando frágeis sinais de recuperação, neste ano de 2019, embora sejam muitos os desafios a serem vencidos pela equipe econômica para o país voltar aos níveis de crescimento desejáveis. Em outubro deste ano a taxa básica de juros definida pelo Banco Central chegou ao patamar mais baixo em muitos anos $(5 \% \mathrm{a} / \mathrm{a})$, com uma taxa anual de inflação também igualmente baixa, estimada em 3,5\% (NÓBREGA, 2019).

Este cenário tem afetado o modus operandi do mercado financeiro brasileiro de maneira significativa. Após décadas de elevadas taxas de juros, o mercado financeiro de renda fixa deixa de ser uma opção muito atraente para investidores. Pesquisas recentemente realizadas pela corretora de valores XP Investimentos e publicadas recentemente pela Infomoney (CUTAIT, 2019), empresa especializada em investimentos pessoais, estimam que, já em 2019, a taxa básica de juros (Selic) possa chegar ao nível mais baixo da história recente do país, entre 4,0\% e 4,5\% a/a (Figura 1).

Esta taxa pode fazer com que investimentos em papéis de renda fixa venham inclusive a ter rendimentos negativos, algo inédito no cenário nacional (LARGHI, 2019). 
Figura 1 - Expectativas dos índices IPCA, PIB e taxa SELIC para o final de 2019, segundo gestores de fundos consultados pela XP investimentos

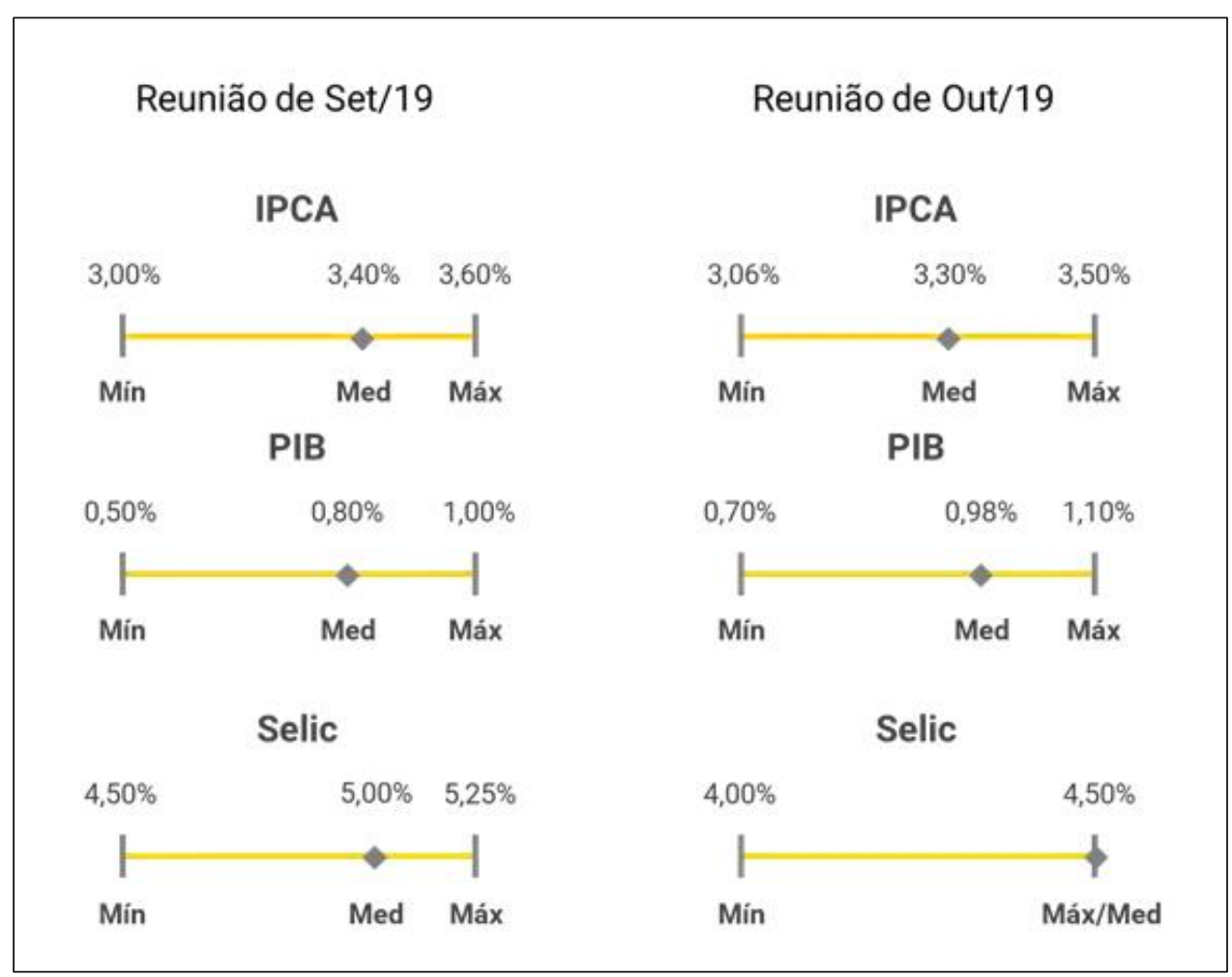

Fonte: Infomoney (2019)

Um resultado dessas mudanças tem sido a corrida de investimentos para outras modalidades, com níveis um pouco maiores de risco, com destaque para os Fundos Imobiliários (BALASSIANO, 2019).

O mercado imobiliário brasileiro, e o carioca em particular, tem se mostrado muito aquecido na última década. Com seu "pico" no momento que ficou conhecido como "boom imobiliário", referente ao período de 2011 a 2013, a despeito de alguns altos e baixos, investir em imóveis não deixou de ser uma boa opção no cenário fluminense (DURÃO, 2019). No presente momento, com o cenário alterado das taxas de juros, a expectativa é de que parte dos recursos dedicados a títulos de renda fixa sejam direcionados para esse mercado (BALASSIANO, 2019).

Uma parcela do resultado/retorno de quem investe no setor imobiliário pode vir da locação desses imóveis ou de sua venda. De uma forma ou outra, um passo fundamental no processo de escolha de local e do tipo de imóvel a 
investir, é a estimativa de seu valor de mercado. No âmbito dos imóveis para fins comerciais este passo é particularmente importante.

A avaliação de imóveis está longe de ser uma ciência exata. São muitas as variáveis em jogo e muitas vezes de caráter subjetivo. Quais seriam essas variáveis e quais seriam as mais e menos relevantes para fins de avaliação do valor de um imóvel? Estes são alguns dos dilemas pelos quais passam aqueles que atuam no setor.

Guili Chor (2019), vice-presidente e acionista da TGB, empresa de gestão patrimonial focada no mercado imobiliário, afirma que a avaliação de investimento para compra de imóveis comerciais costuma ser feita através do cálculo do rendimento desejado em relação ao aluguel potencial do imóvel. As principais características para a determinação do valor de um aluguel seriam a projeção de crescimento da região, o fluxo de passantes, o número de imóveis semelhantes nas proximidades e a capacidade do imóvel de atrair os pedestres, convertendo-os em consumidores. Essa atração, por sua vez, seria gerada pela estética, comodidade e visibilidade do imóvel. Dessa forma, os valores de venda, compra e locação de um imóvel estão relacionados a seus aspectos físicos e como são capazes de influenciar os consumidores.

De acordo com Sheth, Mittal e Newman (2001), para que uma organização tenha sucesso é necessário compreender as necessidades dos consumidores e quais suas motivações para determinadas decisões de compra e uso de produtos e serviços. No âmbito do setor imobiliário comercial é necessária a compreensão dos motivos que levam à captação de pedestres, tornando-os consumidores, uma vez que seus padrões de consumo são parte crucial para a definição do valor do aluguel e, consequentemente, do preço de compra e venda de um determinado imóvel.

Apesar da tendência de crescimento das compras online, a I-scoop (2016), empresa belga de consultoria, afirma que $90 \%$ de todas as compras do varejo no mundo ainda são feitas nas lojas físicas. E segundo a mesma fonte, quando pesquisada a razão, percebeu-se que dois dos nove principais motivos foram a experiência da loja, com $15 \%$ das citações, e o layout da loja, com $13 \%$ das respostas, ambos relativos a aspectos do ambiente físico (Figura 2). 
Figura 2 - Principais motivos para consumo no varejo físico

\begin{tabular}{|rr}
\hline $17 \%$ & Opções de Delivery \\
\hline $17 \%$ & Produtos Novos \\
\hline $17 \%$ & Disponibilidade de Produtos \\
\hline $15 \%$ & Experiência na Loja \\
\hline $14 \%$ & Programas de Fidelidade \\
\hline $13 \%$ & Layout da Loja \\
\hline $13 \%$ & Tecnologia da Loja \\
\hline $10 \%$ & Sustentabilidade \\
\hline $10 \%$ & Mídia Social ou Presença Online
\end{tabular}

Fonte: Adaptado de I-Scoop (2016)

Para Parente (2000), a forma como uma empresa é percebida no mercado está intimamente ligada à sua forma, sua imagem e sua aparência. Essas características, por sua vez, são traduzidas em parte através da identidade dos espaços físicos de seus pontos de venda e de suas marcas, componentes dos esforços mercadológicos para um alcance de um posicionamento de imagem, em especial no caso de lojas de varejo.

Levando em consideração que o ambiente físico de uma loja é um fator relevante para as tomadas de decisão de compras dos consumidores, e que há várias características de imóveis que afetam seu valor, um problema relevante é identificar quais seriam os aspectos que compõem o imóvel em si e o ambiente das lojas que seriam mais relevantes para chamar a atenção dos consumidores. E, eventualmente, como podemos utilizá-los para potencializar as vendas e consolidar o valor de lojas de rua.

\subsection{Objetivo Principal}

O objetivo deste estudo é identificar como determinadas características do imóvel e de seu ambiente físico são capazes de influenciar as percepções dos potenciais consumidores (prospects) em relação a lojas de varejo. Essa identificação tem o potencial de transformar o fluxo de pessoas na região em visita ao espaço físico comercial, fenômeno que aumenta a possibilidade de vendas, consequentemente impactando na avaliação do imóvel. 


\subsection{Objetivos Intermediários}

Para atingir o objetivo final do estudo será necessário decompô-lo em objetivos intermediários, de forma a construir uma compreensão mais detalhada sobre $o$ assunto.

Primeiro será necessário identificar e listar as variáveis que afetam a avaliação de um ponto de venda, sob a ótica do setor de transações imobiliárias.

Em segundo lugar, identificar e listar quais são os fatores (variáveis) que poderiam impactar nas vendas de lojas de varejo, sob o ponto de vista de potenciais consumidores (prospects).

Em terceiro lugar, identificar quais dessas variáveis têm maior e menor efeito na percepção dos consumidores, no que tange sua "propensão à visita", ou na "atratividade" do ponto de venda.

\subsection{Delimitação do Estudo}

O estudo é restrito ao público da cidade do Rio de Janeiro. Essa medida visa isolar os efeitos das mudanças culturais nas diferentes regiões geográficas e seus efeitos nos padrões de compra e consequente avaliação imobiliária. $O$ Rio de Janeiro foi escolhido por ser a cidade de mais fácil acesso ao pesquisador.

Apesar de existirem diversas classificações de imóveis comerciais e diferentes definições de varejo, este estudo irá se limitar apenas aos imóveis urbanos de uso comercial e localizados em ruas. Esta escolha se deve ao fato de lojas em shopping centers e centros comerciais dependerem muito da gestão e posicionamento do empreendimento em si. Ainda, é grande o número de pontos lojas de rua na cidade do Rio de Janeiro.

Devido à dificuldade de conseguir dados de vendas de lojas do varejo $\mathrm{e}$ associá-los diretamente a uma característica específica de imóvel, a pesquisa em questão levará em consideração apenas as impressões dos consumidores, em especial no que diz respeito às opiniões e intenções relacionadas à atratividade dos pontos de venda. 
Por último, será necessário delimitar o número de características a serem estudadas, uma vez que a totalidade de variáveis que compõem o ambiente físico é demasiadamente grande e não haveria tempo hábil ou mão de obra suficiente para avaliá-las. Desta forma, este estudo focará em apenas 4 variáveis, conforme definidas mais adiante.

\subsection{Justificativa e Relevância do Estudo}

A partir dos resultados obtidos neste estudo será possível melhor compreender aspectos físicos que impactam consumidores no momento da escolha de um ponto comercial. Estas variáveis poderão ser consideradas quando da implantação de uma loja do setor de varejo.

Para as lojas já montadas ou operantes, a compreensão de como o ambiente físico pode afetar a percepção dos consumidores, e consequentemente as vendas, pode ser um fator para realização de reformas, visando o aumento da atratividade de seu ambiente e o melhor entendimento das fontes de fluxos.

Outro público que pode vir a ser beneficiado pelo estudo são os investidores do ramo imobiliário comercial, uma vez que a análise de compra de uma loja muitas vezes é realizada sobre as vendas potenciais.

Por fim, este estudo pode vir a se mostrar útil para estudantes de Administração de Empresas, com ênfase em Marketing ou Finanças, como para estudantes de Arquitetura e Urbanismo que busquem um melhor entendimento do impacto arquitetônico de projetos urbanos e do mercado de varejo de forma geral, para aprimoramento profissional. 


\section{Referencial Teórico}

Neste tópico são apresentados aspectos conceituais e estudos relacionados ao tema de pesquisa que servirão de base para a análise realizada.

Desta forma foram abordados os tópicos imóveis, avaliação imobiliária, varejo, ferramentas de marketing, marketing de serviços, evidências físicas (palpabilidade), antropologia do consumo, comportamento do consumidor e influências no comportamento de compra.

\subsection{Setor Imobiliário}

Para a ABNT (2001, p.4), um imóvel é um "bem constituído de terreno e eventuais benfeitorias a ele incorporadas. Pode ser classificado como urbano ou rural, em função da sua localização, uso ou vocação". Os imóveis rurais possuem subclassificações quanto à sua exploração ou sua dimensão (ABNT 2004) enquanto os urbanos são subdivididos por uso, tipo e agrupamento dos imóveis (ABNT 2011).

Em relação ao uso, podem ser classificados como residencial, comercial, industrial, institucional (sedes e escritórios) ou misto. Já no que diz respeito à divisão por tipo, o imóvel pode ser definido como terreno, apartamento, casa, escritório, loja, galpão, vaga de garagem, misto, hotelaria, cinema e teatro, clubes ou prédios industriais. Quanto ao seu agrupamento, os imóveis podem ser analisados de forma isolada ou em conjunto, o que pode vir a alterar a nomenclatura de sua tipologia como no caso de galerias, condomínios, entre outros (ABNT 2011).

Segundo determina o art. 1.142 do Código Civil Brasileiro (Brasil, 2002), considera-se estabelecimento comercial todo complexo de bens, sejam eles tangíveis ou intangíveis, utilizados para exercício de atividade empresarial, por empresário ou sociedade empresária. 


\subsection{Avaliação Imobiliária}

Conforme a ABNT (2001), o processo de avaliação imobiliária no Brasil é relativamente recente e teve seu início na década de 1950. Apesar disso, a primeira norma brasileira só surgiu em 1977 e seu registro no INMETRO só ocorreu em 1989, ambos através da NBR 5676.

Ainda de acordo com a mesma fonte, existem quatro metodologias de avaliação imobiliária, sendo elas: o método comparativo de mercado, ou seja, a comparação entre imóveis através de seus atributos; método da renda, via cálculo da renda prevista pelo retorno percentual esperado; método evolutivo, que consiste no valor do imóvel como soma do valor de seus atributos; e o método involutivo, estudo de viabilidade técnico-econômica de um possível empreendimento.

Apesar da variedade de metodologias, a Comissão Técnica Nacional de Investimentos Imobiliários (2016) declara que, de forma geral, o método mais utilizado no mercado é o método comparativo de mercado, seguido pelo método da renda, utilizado especialmente no caso de aquisições.

O fato do método comparativo se basear na interpretação do avaliador em relação às similaridades dos imóveis faz com que ele se torne extremamente subjetivo. Dessa forma, os investidores em imóveis comerciais costumam complementar suas análises realizando o método da renda. Isso faz com que seja importante compreender os fatores que tornem um imóvel atrativo para os varejistas (CHOR, 2019).

\subsection{Varejo}

De acordo com a visão de Kotler (2000, p.540), "o varejo inclui todas as atividades relativas à venda de produtos ou serviços diretamente aos consumidores finais, para uso pessoal e não comercial". Ainda sobre o comércio varejista, Kotler (2000, p.482) afirma que "qualquer organização que venda para consumidores finais - seja ele um fabricante, atacadista ou varejista - está fazendo varejo". 
Kotler (2000) classifica algumas tipologias de varejo, sendo elas: loja de especialidade, loja de departamento, supermercado, loja de conveniência, loja de descontos, varejista off-price (liquidação), loja de fábrica, loja de descontos independentes, clube atacadistas, superloja, lojas combinadas, hipermercados e showroom de vendas por catálogo.

Las Casas (2000) afirma que a essência do varejo está ligada à comercialização de produtos ao consumidor final, independente das diversas definições sobre o assunto. Além disso, o autor afirma que o consumidor é o centro do comércio e por isso é necessário adquirir informações diretamente com ele a fim de compreender suas necessidades.

\subsection{Ferramentas de Marketing}

Kotler faz um paralelo direto entre a compreensão das necessidades dos consumidores e a área de marketing ao defender que "para prever as reações dos compradores a diversas características, estilos e outros atributos, as empresas devem recorrer à pesquisa de marketing" (KOTLER, 2000, p.122). E complementa: "uma oportunidade de marketing existe quando a empresa pode lucrar ao atender às necessidades dos consumidores de um determinado segmento" (KOTLER, 2000, p.98).

Fraga (2006) também faz uma associação direta entre os consumidores e o trabalho de marketing, uma vez que ele define esse último como sendo o estudo de mercado, responsável por observar as tendências e criar novas oportunidades de consumo visando à satisfação dos clientes.

Para a American Marketing Association (AMA, 2017) o marketing seria a "atividade, conjunto de instituições, e processos para criação, comunicação, entrega e troca de ofertas que tenham valor para consumidores, clientes, parceiros, e a sociedade de forma geral".

Segundo Sobral e Peci (2008), o mix de marketing é a parte do processo de administração de marketing responsável pela criação e captura de valor para os consumidores. O mix tradicional está divido em Produto, incumbido dos atributos e características do produto ou serviço oferecido; Praça, que compreende elementos da distribuição e logística; Promoção, responsável pela 
comunicação da marca com os consumidores; e Preço, referente aos métodos e valores de transação (Figura 3).

Figura 3 - Processo de Administração de Marketing

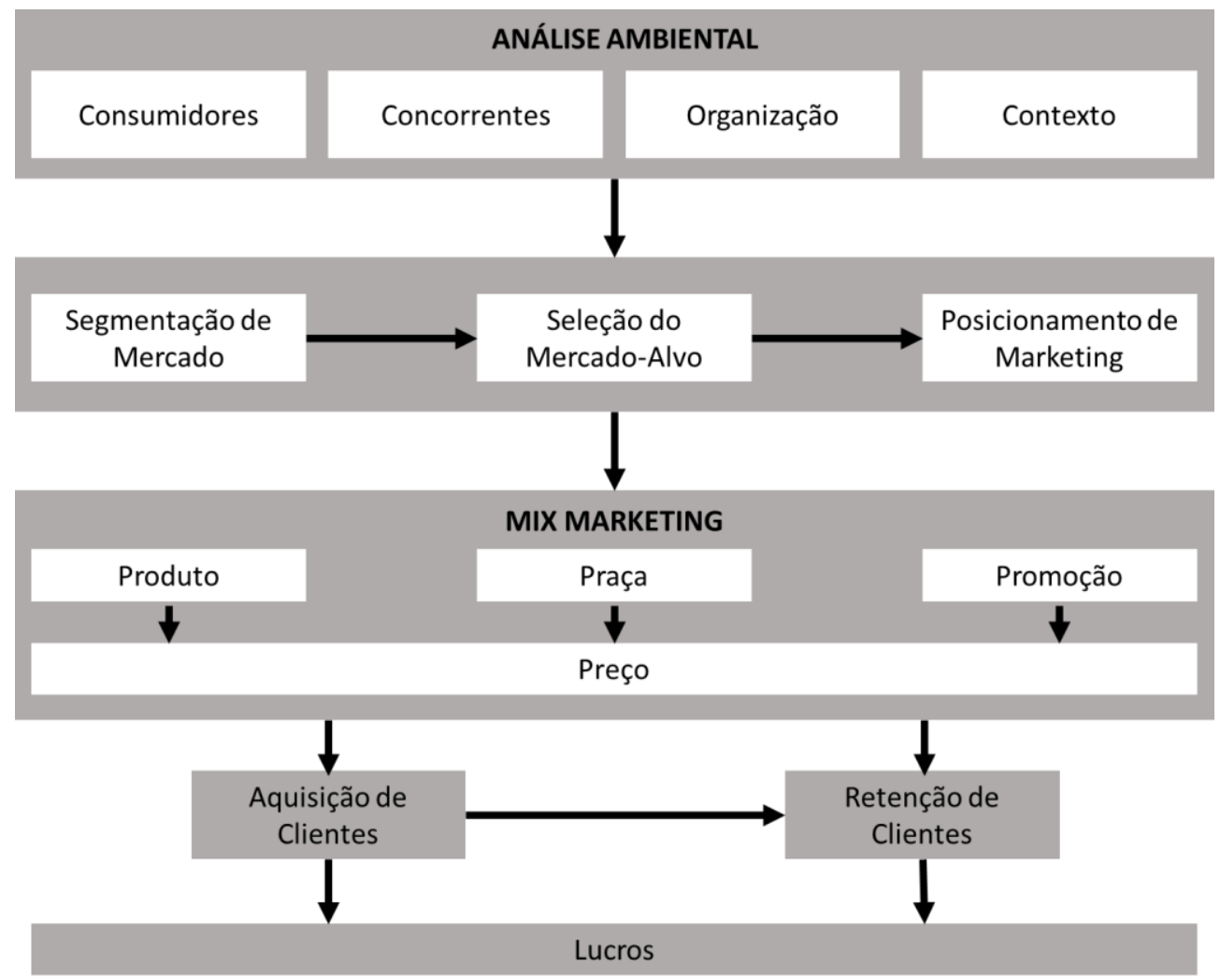

Fonte: Adaptado de Sobral e Peci (2008, p.300)

Peter Drucker (apud COBRA, 1992), teórico de renome no âmbito da administração, afirma que sempre haverá a necessidade de esforços relacionados a vendas. Porém, tornar este esforço de venda supérfluo é o maior objetivo de marketing, uma vez que ele busca que o produto ou serviço se venda por si só, precisando apenas estar disponível de forma conveniente ao mercado.

\subsection{Marketing de Serviços}

Para Futrell (2014), o processo de vendas, considerado o coração do varejo, seria uma espécie de serviço, uma vez que seu resultado não é tangível, mas sim uma forma de conectar necessidades com soluções.

Segundo Levitt (1988, p.142), "a diferença entre marketing e vendas é mais do que semântica: vendas têm seu foco nas necessidades do 
representante; marketing nas do comprador. Vendas preocupam-se com a necessidade do representante de converter seu produto em dinheiro; marketing preocupa-se com a ideia de satisfazer as necessidades do consumidor com o produto“.

Para Kotler (2000), um serviço seria qualquer esforço intangível oferecido a outra pessoa ou empresa no qual não há transferência de propriedade. Ele completa afirmando que um serviço pode ou não estar ligado a um produto concreto. Dessa forma, serviços ocorrem em todas as empresas em maior ou menor escala. Esta afirmação pode ser interpretada como um desenvolvimento do conceito de espectro de intangibilidade proposto por Shostack (1977), no qual ele afirma existir um continuum no nível de intangibilidade de bens e serviços, podendo ser classificados como produtos puros, híbridos e serviços puros (figura 4). Grande parte dos autores estudados parece concordar que os serviços possuem quatro características distintas dos produtos, sendo elas a intangibilidade, a inseparabilidade, a perecibilidade e a variabilidade.

Figura 4 - Continuum de Bens e Serviços

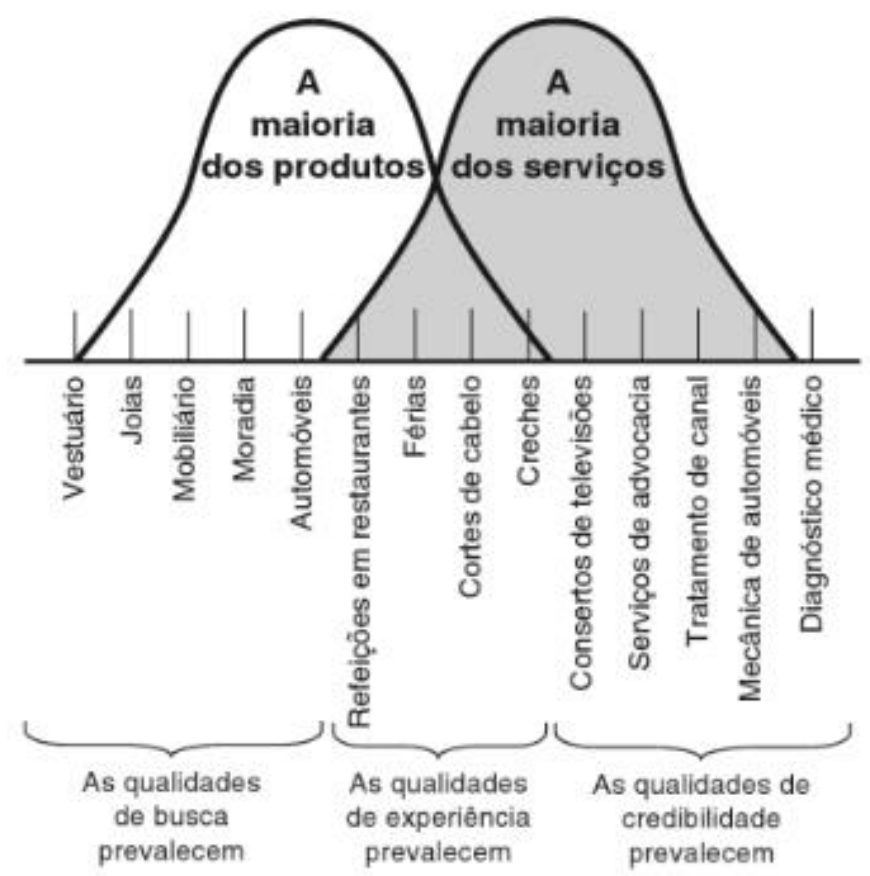

Fonte: Zeithalm et al. (2014, p.24)

De acordo com Zeithaml, Bitner e Gremler (2014), devido ao fato dos clientes estarem presentes na produção de serviços e necessitarem de aspectos 
tangíveis, passou a ser adotado o conceito de mix expandido de serviços, que consiste na adição dos conceitos de pessoas, processos e evidências físicas (palpabilidade), além do mix original composto por preço, praça, produto e promoção. Assim sendo, o chamado marketing mix, quando aplicado a serviços, é composto por sete áreas de atuação, e em referência específica ao presente estudo, as evidências físicas, ou palpabilidade, são de especial interesse.

\subsection{Evidências Físicas (Palpabilidade)}

Para Zeithaml, Bitner e Gremler (2014, p.27), evidências físicas (ou as palpabilidades) são parte do marketing mix de serviços que se definem como "o ambiente em que o serviço é consolidado e em que a empresa e o cliente interagem, do qual fazem parte muitos componentes tangíveis que facilitam o desempenho ou a comunicação do serviço".

Kotler (2000, p.548) cria um paralelo direto entre a capacidade de vendas de uma loja e seu ambiente físico ao afirmar que "O ambiente é um outro aspecto importante para as lojas. Todas as lojas têm um layout físico que pode facilitar ou dificultar a movimentação das pessoas em seu interior. Toda loja tem um "visual". A loja deve incorporar um ambiente planejado que seja adequado ao mercado-alvo e atraia clientes, favorecendo as compras".

Baker (1986) sugere que o ambiente físico pode ser quebrado em três fatores, sendo eles: fatores do ambiente, as condições sutis do ambiente, tais como temperatura, barulhos e cheiros, entre outros; fatores de design, estímulos diretos como arquitetura, estilo, forma, layout e afins; fatores sociais, a quantidade de pessoas, como elas se comportam e qual sua aparência, sejam elas clientes ou funcionários.

Ornstein, Bruna e Roméro (1995) abordam as diferentes interações entre o ambiente físico e o impacto no comportamento do consumidor e as classificam em quatro grupos (figura 5). Ambiente construído, relacionado aos aspectos arquitetônicos; condições de conforto, ligadas às condições que se encontram o espaço; tipo de trabalho, voltado ao impacto do ambiente nas tarefas realizadas; e relações pessoais, o ambiente como facilitador ou não de interações sociais. 
Figura 5 - Categorias de impacto do ambiente no comportamento

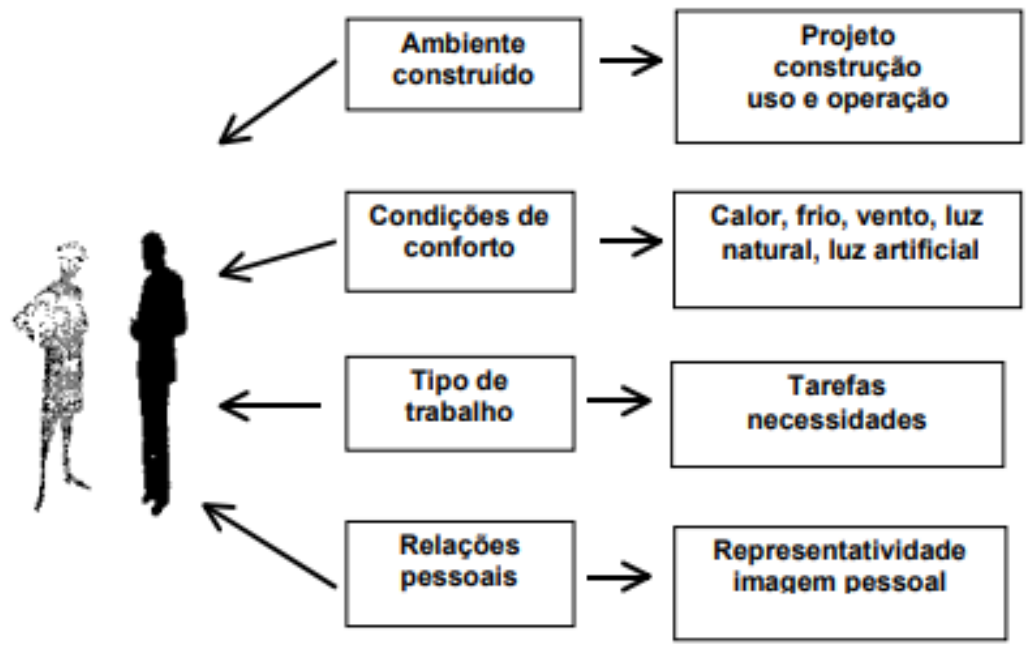

Fonte: Ornstein, Bruna e Roméro (1995)

Outra divisão para o ambiente de um ponto de venda foi proposta por Zorrilla (2002), dividindo-o em quatro segmentos designados: exterior, condições ambientais, interior e social. Segundo ela, as evidências físicas têm forte impacto na percepção de qualidade de produto, na imagem e posicionamento de marca e na experiência de compra como um todo. Se bem gerenciado, o ambiente físico pode se tornar um fator para aumentar a fidelidade e satisfação dos consumidores, podendo aumentar a rentabilidade do estabelecimento.

Geargeoura e Parente (2009) propõem a existência de duas formas distintas de apresentação de um ponto de venda, sendo elas as apresentações externas e internas. As externas seriam aquelas relacionadas à posição da loja e sua visibilidade na vizinhança, a arquitetura (estilo, recuo da rua entre outros) e elementos adicionais de comunicação, como placas e vitrines. No caso das internas, seriam aqueles referentes a elementos sensoriais, como cores, iluminação, estímulos táteis, odores e sons; elementos de comunicação, tais como etiquetas informativas e os funcionários; e elementos de conforto relacionados à largura da circulação, localização dos caixas, manutenção, limpeza, entre outros.

Engel, Blackwell e Miniard (2000) por sua vez, separam os aspectos relacionados às evidências físicas através do efeito que possam ter no consumidor. Dessa maneira, eles propõem uma subdivisão em cinco grupos, sendo eles: layout, o que facilita o cliente encontrar um determinado produto; 
cores, que criam estímulos sensoriais; materiais de ponto de venda, que capturam a atenção dos clientes e estimulam a compra; vendedores, capazes de influenciar as vendas diretamente; e aglomeração, a quantidade de consumidores dentro do estabelecimento.

Sherman, Mathur e Smith (1997) buscaram entender o paralelo entre o ambiente e os estados emocionais dos consumidores através da avaliação do impacto de diversos fatores de design no comportamento do consumidor. A partir desse estudo eles elencaram alguns fatores que consideraram de alta relevância para o tema, sendo eles: dimensão dos espaços de circulação, exposição das mercadorias, limpeza e organização.

Russell e Mehrabian (1976), psicólogos pioneiros nos estudos dos impactos ambientais nos indivíduos, reconheceram que os estímulos do ambiente são capazes de influenciar diretamente no estado emocional de um determinado indivíduo e, consequentemente, em suas ações.

Berry e Parasuraman (2004) citam que a principal responsabilidade do gerente de marketing de serviços é gerenciar aspectos tangíveis para que os sinais sobre os serviços sejam enviados. Além disso, afirmam que o ambiente físico é capaz de nutrir a atitude e o comportamento desejado durante o encontro do serviço.

\subsection{Antropologia do Consumo}

Kant (2006) deu origem ao termo antropologia e o definiu como ciência metafísica da experiência do homem. Para Kant (2006), a antropologia possui um caráter de doutrina de observação, focado especialmente na compreensão dos sentimentos ligados ao desejo, prazer e dor.

Para Frost e Hoebel (2006), a antropologia é uma ciência que busca explorar a natureza do homem, como criatura em constante evolução presa a uma cultura e organizada em sociedade. Para isso, é necessário que se estudem sistematicamente todas as manifestações de atividade do ser humano e como elas estão interligadas, sejam elas econômicas, sociais, culturais, habitacionais, biológicas etc. 
De acordo com Migueles (2007), a antropologia do consumo seria um estudo antropológico com foco na visão mercadológica. Logo seria uma forma de pensar o homem em seus múltiplos papeis e funções e como eles se manifestam a partir de nossos padrões de consumo. Ou seja, é o estudo das variáveis que levam um consumidor a adotar um determinado comportamento.

\subsection{Comportamento do Consumidor}

De acordo com Solomon (2016), comportamento do consumidor seria tudo aquilo relacionado ao processo em que um indivíduo se envolve na seleção, compra, utilização ou disposição de qualquer natureza para satisfazer necessidades e desejos.

A imagem, a aparência e a forma como uma empresa se comunica com os consumidores determina o posicionamento de mercado do varejista (PARENTE, 2000). O comportamento do consumidor inclui todas as características do ambiente que influenciam os pensamentos, os sentimentos e ações dos consumidores (LUCCHESE e RIBEIRO, 2012), moldando suas atitudes (percepções) e formas de agir (comportamentos).

Uma vez que a função central de marketing é alcançar a satisfação das necessidades do consumidor, entender seu comportamento através do processo de decisão envolvido na compra de um determinado produto ou serviço é primordial. Seguindo esse raciocínio, Sobral e Peci (2008) propuseram o seguinte modelo para mapear as etapas do processo de decisão de compra (figura 6): 
Figura 6 - Etapas do processo de decisão de compra

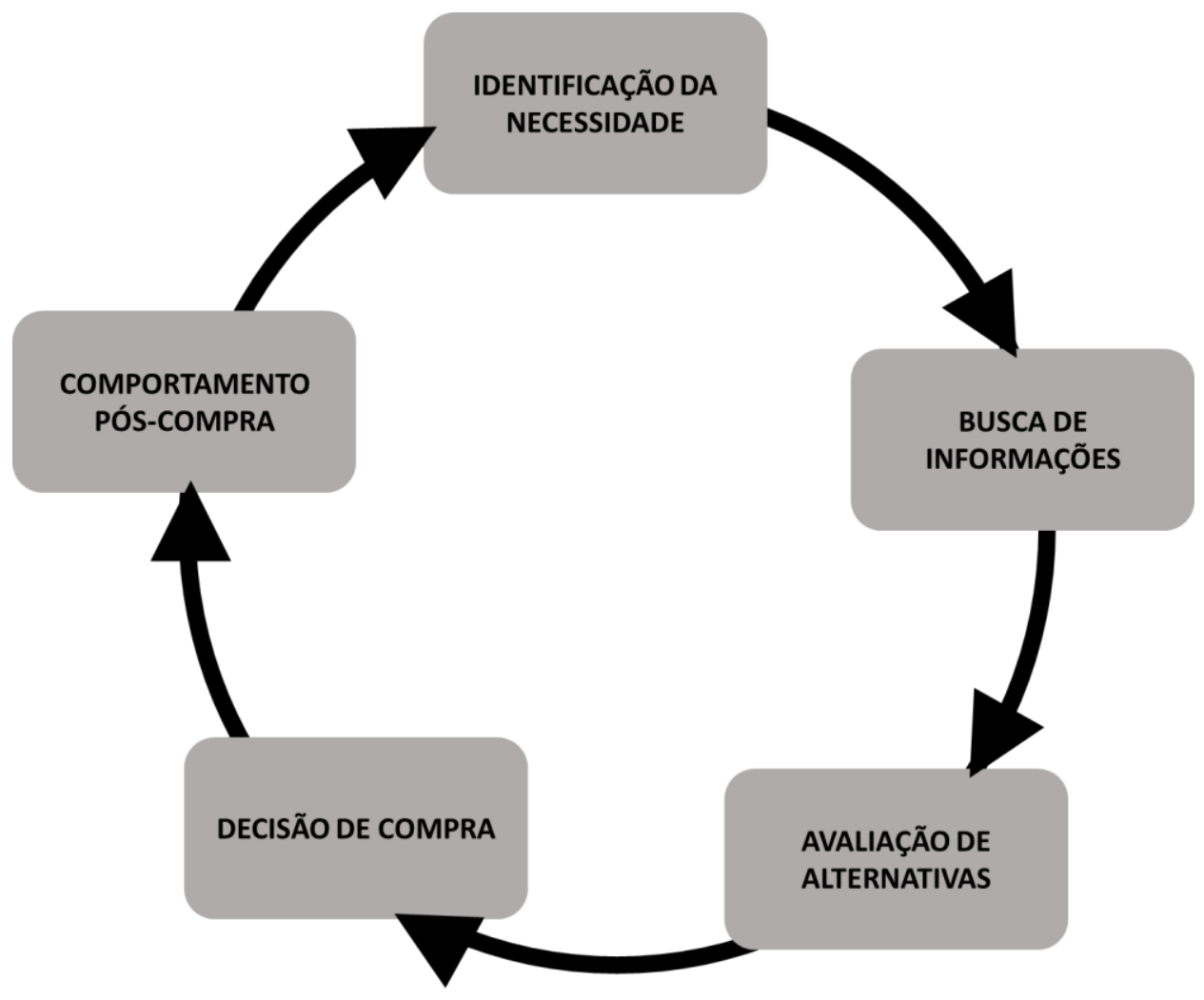

Fonte: Adaptado de Sobral e Peci (2008, p.305)

No modelo proposto, a identificação da necessidade seria a primeira etapa de compra e essa poderia ser despertada por estímulos internos, como sede e fome, ou externos, gerados pela publicidade e exposição, por exemplo. A partir desse ponto o cliente irá buscar informações referentes ao produto através de fontes pessoais (como amigos e família), comerciais (vendedores, propaganda), pública (mídia, órgãos de defesa do consumidor) e experimentais (provas, manuseio). Ao se sentir confortável com o nível de informações reunidas o consumidor irá compará-las com o conhecimento que já possui das alternativas selecionadas, com o objetivo de mensurar qual delas melhor atenderá suas necessidades. A partir desse ponto ele tomará a decisão de compra do produto ou serviço. Caso ele decida pela compra e consequente uso ou consumo, realizará uma avaliação do resultado em relação às suas expectativas, o que pode levar a uma recompra ou não. 


\subsection{Influências no Comportamento de Compra}

A visão tradicional do marketing divide as atitudes dos consumidores em três componentes: cognitivo, afetivo e conativo. O componente cognitivo está relacionado a crenças, conhecimentos e informações do consumidor, ou seja, a compreensão que ele possui sobre o produto ou serviço. O componente afetivo é referente aos sentimentos e emoções despertadas. Em outras palavras, as sensações pessoais. Por fim, o conativo diz respeito às intenções, sejam elas comportamentais, de compra ou consumo, ou seja, as ações envolvidas no processo (ENGEL, MINIARD, BLACKWELL, 2000).

Porém, os mesmos autores apresentam uma visão mais contemporânea da relação entre esses componentes (Figura 7).

Figura 7 - Modelo contemporâneo de influência de compra

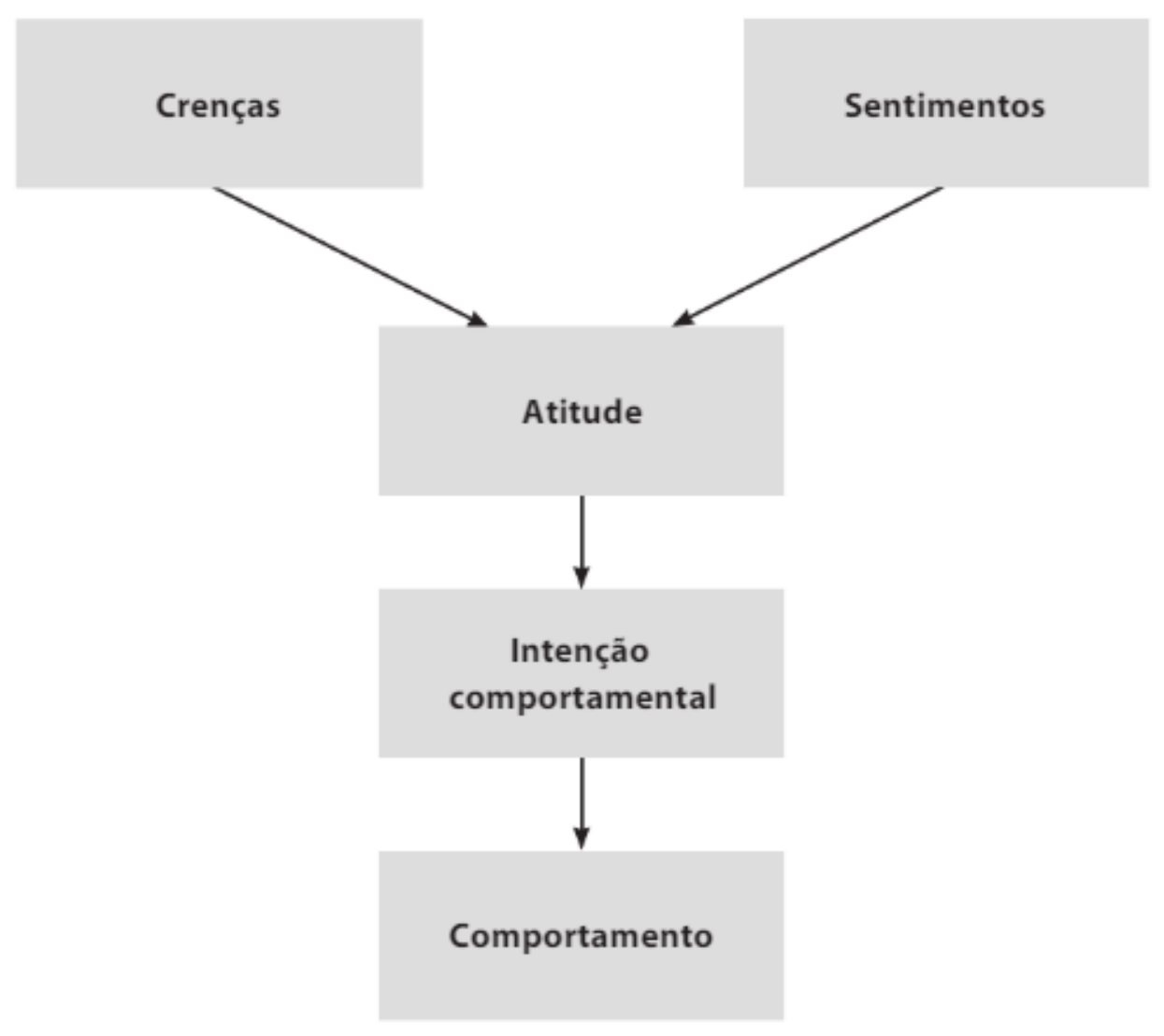

Fonte: Engel, Blackwell e Miniard (2000) 
Nesse novo modelo, as crenças (cognitivo) e sentimentos (afetivo) seriam os responsáveis pela formação das atitudes. Essas, por sua vez, seriam as vontades e impulsos que podem ou não levar à intenção de compra (conativo). Uma vez consolidada a intenção de compra, caso não haja impedimentos ou complicações, o próximo passo será a realização do comportamento de compra propriamente dito, a ação de consumo. Dessa forma eles demonstram uma maior importância à intenção de compra do que a atitude em si, uma vez que ela está mais próxima da compra em si.

Kotler (2000) propõe outro modelo para explicar influências sobre o comportamento de compra dos consumidores. Em sua visão, para vender um determinado produto é necessário entender os fatores que levam os consumidores a comprá-los. Dessa forma, ele elenca quatro principais fatores que teriam influência direta no processo de compra: culturais, sociais, pessoais e psicológicos (Figura 8).

De acordo com Sobral e Peci (2008, p. 304), "Dentre os diversos fatores ambientais a cultura é um dos principais determinantes do comportamento do consumidor. É por meio da cultura que uma pessoa adquire valores, crenças, costumes e preferências, que a levarão a adotar determinado comportamento de consumo". Essa afirmação corrobora a visão de Kotler (2000) de que a cultura seria o valor mais importante por ser o valor que cresce com o indivíduo.

Os fatores sociais dizem respeito aos diferentes grupos que exercem alguma influência, seja ela direta ou indireta, sobre o processo decisório de compra do consumidor (SILVA, 2006). Durante o processo de compra o consumidor irá levar em consideração o meio em que vive, as pessoas com as quais se relaciona e suas reações ao produto ou serviço consumido (SOBRAL e PECI, 2008).

Segundo Kotler (2000), os fatores pessoais seriam referentes às diferentes posições que um determinado indivíduo ocupa na sociedade e em seus grupos. Esses, por sua vez, seriam compostos por idade, ocupação, condição econômica, entre outros.

Os fatores psicológicos são referentes ao estado emocional do comprador, às vivências individuais pelas quais passou e suas crenças e 
motivações pessoais (KOTLER, 2000). Em outras palavras, estariam intimamente ligados à personalidade própria de cada consumidor (SOBRAL e PECI, 2008).

Figura 8 - Fatores que influenciam no comportamento

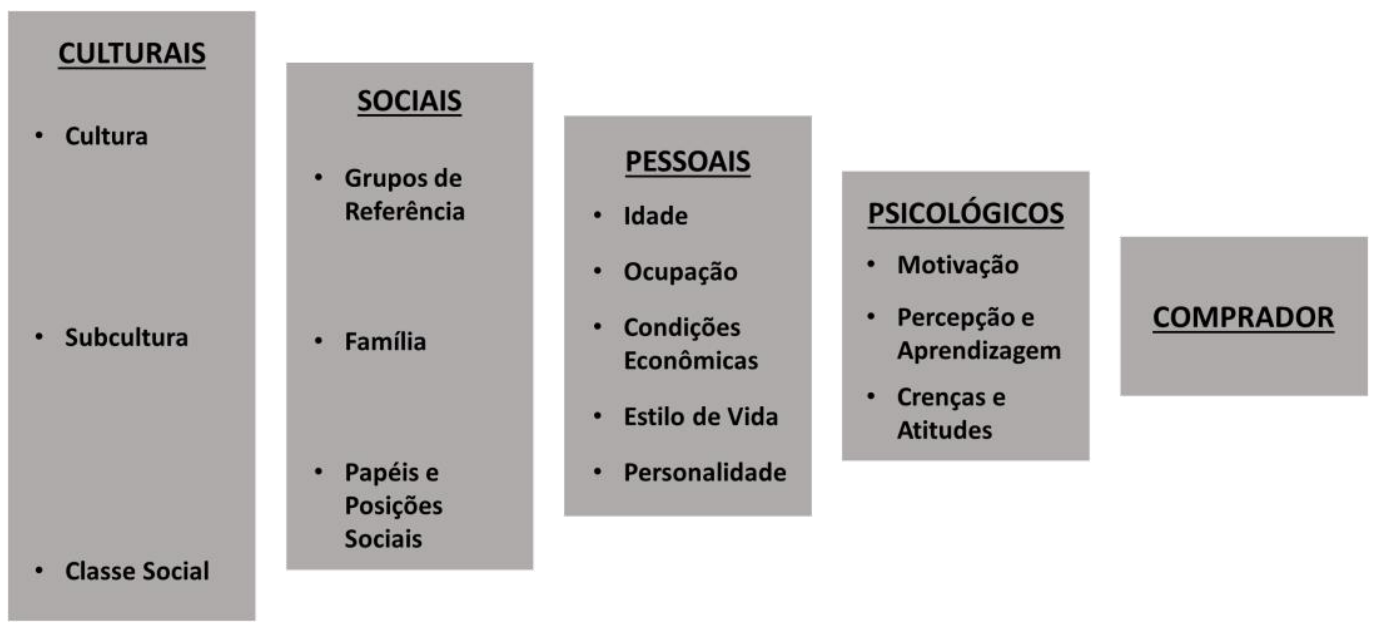

Fonte: Adaptado de Kotler (2000)

Para Engel, Blackwell e Miniard (2000), precisamos entender o processo envolvido na tomada de decisões e as influências que ele sofre para que possamos compreender porque os consumidores compram ou não determinado produto, ou compram ou não em determinada loja, uma vez que eles tendem a escolher aqueles que foram mais bem avaliados. Parte deste trabalho é exatamente identificar variáveis relativas aos atributos físicos de pontos de venda e seus potenciais impactos nas percepções e atitudes dos consumidores. 


\section{Metodologia da Pesquisa}

\subsection{Método de Análise Hierárquica (MAH)}

Quando não há uma escala padrão para se mensurar algo é necessário realizar uma comparação para se chegar a uma medida relativa. Nossos cérebros realizam comparações relativas o tempo todo, porém, o método científico tem negligenciado essa forma de comparação devido à dificuldade de formalizar os resultados com os formatos de medição padrão (SAATY, 2000).

Buscando uma forma de poder mensurar objetivamente as comparações relativas, Thomas L. Saaty desenvolveu o Método de Análise Hierárquica, em 1971. Esse método permite gerar uma hierarquia objetiva da importância de certas características para um objetivo pré-determinado. Devido à sua capacidade de gerar resultados objetivos para problemas de cunho mais subjetivo, o Método de Análise Hierárquica é amplamente utilizado em campos como psicologia, sociologia, ciência política e arquitetura (SAATY e VARGAS, 2001).

Saaty (2000) afirma que para que se possa utilizar o Método de Análise Hierárquica é necessário elencar os critérios a serem aplicados e o número de hierarquias a serem utilizadas, sendo que o primeiro nível hierárquico deve sempre corresponder ao objetivo da pesquisa e, o último, às alternativas. A figura 9 sintetiza essa lógica. 
Figura 9 - Estrutura do Método de Análise Hierárquica

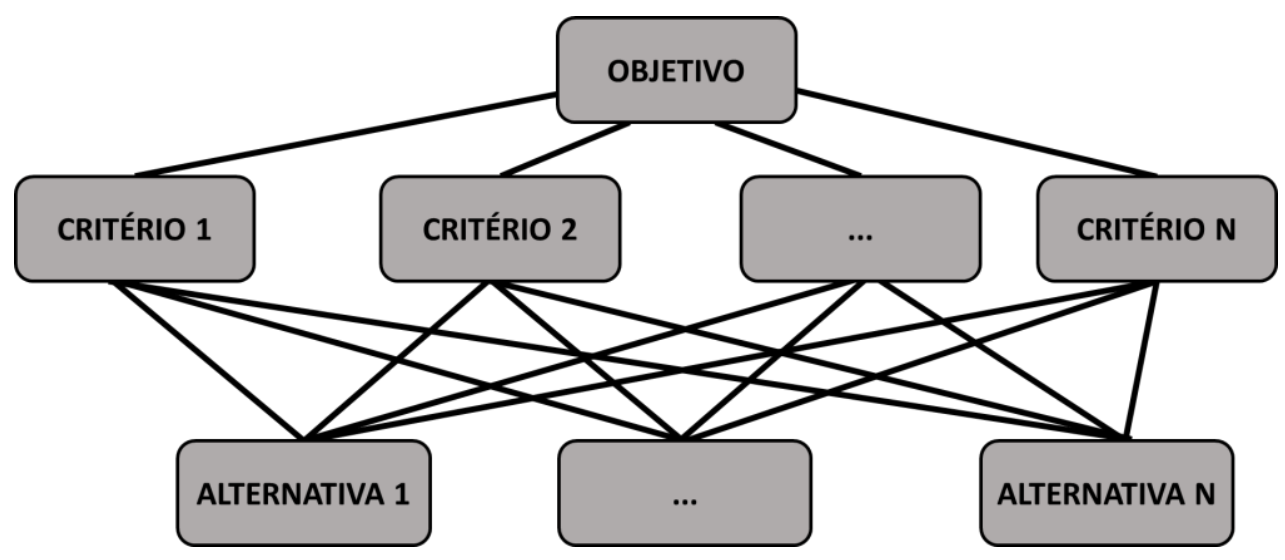

Fonte: Adaptado de Saaty e Vargas (2001)

Para a confecção do presente estudo, foram elencadas quatro hierarquias. O nível mais baixo foi composto por dois conjuntos de características das evidências físicas de uma loja, conforme tratadas no referencial teórico. São eles: os aspectos externos da loja, composto por esquina (posição), recuo, testada (frente de loja) e transparência; e os aspectos internos da loja, referentes à conservação, cores, iluminação e circulação.

Acima dessas características foram selecionados os critérios subjetivos utilizados para a avaliação de atratividade de um imóvel, conforme a literatura estudada: estética (PARENTE, 2000; CHOR, 2019), visibilidade (CHOR, 2019; GEARGEOURA e PARENTE; 2009) e conforto (ORNSTEIN, BRUNA e ROMÉRO, 1995; GEARGEOURA e PARENTE; 2009).

O nível hierárquico imediatamente acima consiste nos critérios de divisão entre características externas e internas, anteriormente mencionados, propostos por Geargeoura e Parente (2009). Os externos seriam aqueles referentes a aspectos construtivos, ou de implantação do imóvel, semelhantes ao conceito de exterior de Zorrilla (2002) e de ambiente construído, conforme proposto por Ornstein, Bruna e Roméro (1995). Já os internos seriam os relativos ao uso e conservação do espaço, análogo à soma das condições ambientais e de interior, conforme proposto por Zorrila (2002) e condições de conforto, conforme Ornstein, Bruna e Roméro (1995). 
O último nível hierárquico corresponde ao objetivo do método. Neste caso, seria elencar a característica de maior impacto entre as alternativas propostas e, consequentemente, hierarquizar os fatores do ambiente físico. A figura 10 resume o processo.

Figura 10 - Estrutura MAH para elaboração da pesquisa

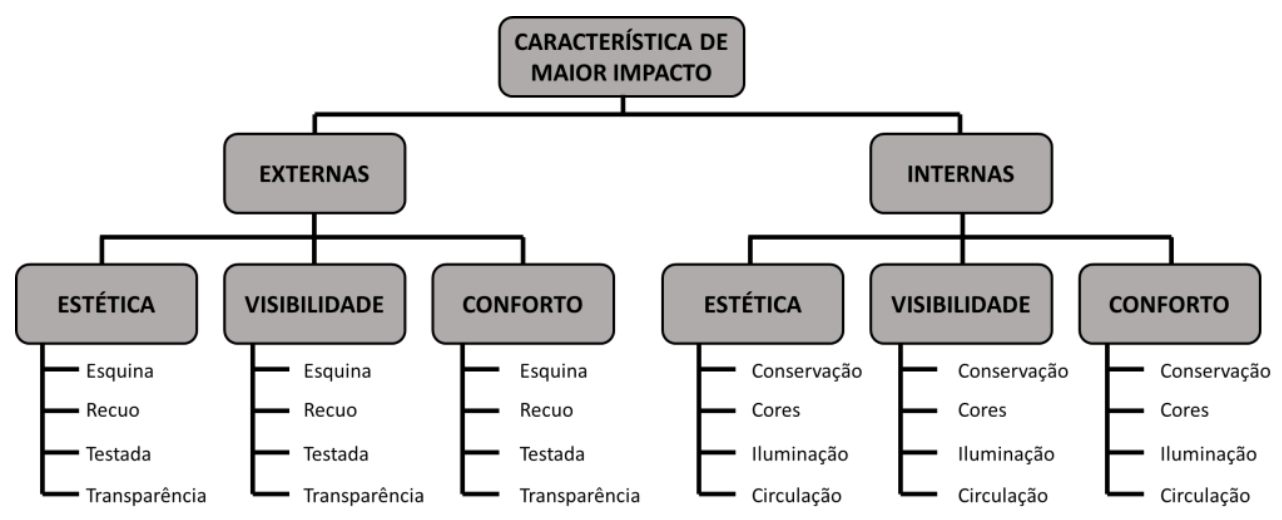

Fonte: Elaboração própria (2019)

O Método de Análise Hierárquica utiliza uma série de comparações par a par de componentes pré-definidos para facilitar 0 estudo de sistemas extremamente intrincados ou com alta subjetividade. Uma vez expressa a preferência, é necessário atribuir um valor numérico para cada comparação, aqui considerando uma escala de 1 a 9 pontos (SAATY e VARGAS, 2001). A tabela 1 traduz as classificações dos nove pontos propostos.

Tabela 1 - Escala fundamental de Saaty

\begin{tabular}{|c|c|c|}
\hline INTENSIDADE & DEFINIÇÃO & EXPLICAÇÃO \\
\hline 1 & Igual Importância & Comparação igual para o objetivo \\
\hline 2 & Importância Fraca & \multirow{2}{*}{$\begin{array}{l}\text { Um objetivo ligeiramente } \\
\text { favorável em relação ao outro }\end{array}$} \\
\hline 3 & Importância Moderada & \\
\hline 4 & Importância Mais Moderada & \multirow{2}{*}{$\begin{array}{l}\text { Um objetivo Fortemente } \\
\text { favorável em relação ao outro }\end{array}$} \\
\hline 5 & Importância Forte & \\
\hline 6 & Importância Mais Forte & \multirow{2}{*}{$\begin{array}{l}\text { Domínio de um objetivo em } \\
\text { relação ao outro }\end{array}$} \\
\hline 7 & Importância Muito Forte & \\
\hline 8 & Importância Muito Mais Forte & \multirow{2}{*}{$\begin{array}{l}\text { Maior ordem de afirmação de um } \\
\text { objetivo em relação ao outro }\end{array}$} \\
\hline 9 & Importância Extrema & \\
\hline
\end{tabular}

Fonte: Adaptado de Saaty (2000) 
Esta escala foi utilizada para extrair dos participantes da pesquisa suas impressões acerca das características de lojas de varejo. Para facilitar essas comparações e a visualização das características previamente citadas de forma isolada, foram criadas imagens em 3D. Essas imagens se referem a fachadas e interiores de lojas, produzidas em software de projetos arquitetônicos e têm como variação as quatro características que distinguem seus aspectos externos e internos (Apêndice A).

A utilização dessa abordagem facilita a coleta de dados e possibilita neutralizar outras variáveis que poderiam comprometer a comparação entre as alternativas. Por exemplo, as imagens não contêm marcas, são da mesma tonalidade de cor e não revelam perfis de lojas vizinhas.

Essa metodologia possui algumas características inerentes, tendo como principal a estruturação de hierarquia para problemas complexos. Outras características relevantes desse método são a identificação de objetivos relevantes, a análise dos critérios que afetam as decisões, a flexibilidade para incorporação em diversos cenários e a objetividade para assuntos subjetivos (SAATY e VARGAS, 2001).

\subsection{Composição dos Grupos Focais}

Satty (2000) afirma que ao aplicar o método de análise hierárquica em grupos se tem uma maior facilidade de compreender o problema, elencar os critérios, estruturar as decisões e discutir os julgamentos. Dessa forma foi decidido que a amostragem seria realizada através do uso de grupos de foco.

Foi definido que a pesquisa seria realizada com dois grupos de foco diferentes, um composto de consumidores em geral e outro de indivíduos que trabalhem no mercado imobiliário. Essa decisão tem como objetivo avaliar as respostas dos grupos separadamente, dessa forma comparando as percepções dos consumidores com as impressões de profissionais de mercado.

O grupo de consumidores foi composto por dez pessoas com características distintas. O intuito foi mesclar perfis que de alguma forma representam a diversidade do universo de consumidores. As idades do grupo 
variaram de 15 a 81 anos e foi representado proporcionalmente entre homens e mulheres.

Já o grupo do setor imobiliário foi composto por seis pessoas de diversos cargos ou papeis dentro desse mercado: corretores autônomos, corretores de imobiliárias, executivos do setor imobiliário e engenheiros civis com atuação na área.

Dado que a coleta de dados foi realizada em momentos separados, para poder ocorrer a comparação foi necessário que ambos os grupos fizessem suas avaliações sobre as mesmas características e critérios, conforme definidos anteriormente.

\subsection{Coletas de Dados}

Conforme mencionado anteriormente, o método de análise hierárquica utiliza uma série de comparações "par a par" nas quais cada um dos grupos focais deve avaliar e dar notas para cada um dos itens da estrutura da pesquisa em relação a cada um dos critérios diretamente superiores.

A partir dos resultados das comparações anteriormente mencionadas, foram geradas matrizes de pares. Já que a importância relativa de um elemento em relação a si mesmo é sempre de igualdade, a matriz possui uma diagonal em que os valores de comparação devem sempre corresponder a 1, conforme ilustrado na tabela 2.

Tabela 2 - Exemplo de matriz comparação antes do preenchimento

Critério de comparação

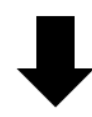

Características comparadas

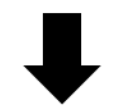

\begin{tabular}{|c|c|c|c|}
\hline Internos & Estética & Visibilidade & Conforto \\
\hline \hline Estética & 1 & & \\
\hline Visibilidade & & 1 & \\
\hline Conforto & & & 1 \\
\hline
\end{tabular}

Fonte: Elaboração Própria 
Para o preenchimento das matrizes deve ser levado em consideração o resultado das comparações par a par. Os elementos devem ser preenchidos de modo que a característica que foi definida como de maior importância na comparação deverá estar no eixo vertical (à esquerda) e a característica a qual ela foi comparada no horizontal (acima).

No seguinte exemplo (Tabela 3), considerando variáveis do critério "ambiente interno", conforme a escala de Saaty, foi atribuído um valor de preferência de intensidade 3 (importância moderada ou ligeiramente favorável) para "estética" em relação à "visibilidade", atribuído um valor 1 (igualdade) para "conforto" em relação à "estética" e um valor de intensidade 3 (importância moderada ou ligeiramente favorável) para "conforto" em relação à "visibilidade".

Tabela 3 - Exemplo de preenchimento das respostas na matriz comparação

\begin{tabular}{|c|c|c|c|}
\cline { 2 - 4 } \multicolumn{1}{c|}{ Internos } & Estética & Visibilidade & Conforto \\
\hline Estética & 1 & 3 & \\
\hline Visibilidade & & 1 & \\
\hline Conforto & 1 & 3 & 1 \\
\hline
\end{tabular}

Fonte: Elaboração Própria

Para que seja possível completar a tabela, os elementos de posição inversa aos preenchidos com respostas devem ser preenchidos como 1/R, no qual $R$ representa a resposta de posição inversa. Ou seja, se um elemento $A_{12}$ foi preenchido com o valor 3 o elemento $A_{21}$ deverá ser preenchido com o valor 1/3.

Tabela 4 - Exemplo de matriz comparação completa

\begin{tabular}{|c|c|c|c|}
\cline { 2 - 4 } \multicolumn{1}{c|}{ Internos } & Estética & Visibilidade & Conforto \\
\hline Estética & 1 & 3 & 1 \\
\hline Visibilidade & $1 / 3$ & 1 & $1 / 3$ \\
\hline Conforto & 1 & 3 & 1 \\
\hline
\end{tabular}

Fonte: Elaboração Própria 


\subsection{Tratamento de Dados}

Após a realização da coleta de dados, é necessário realizar um tratamento dos mesmos a fim de se obter uma hierarquia clara entre as características estudadas.

De acordo com o método, o próximo passo é realizar a normalização dos resultados. Para isso, deve-se dividir cada um dos itens das matrizes pela soma da coluna em que estão inseridos (seu peso proporcional em relação à variável sendo comparada), criando-se uma nova matriz normalizada, cuja soma das colunas deve ser igual a um (tabela 5).

Tabela 5 - Exemplo de matriz normalizada

\begin{tabular}{|c|c|c|c|c|c|}
\hline Objetivo & Externos & Internos & Objetivo & Externos & Internos \\
\hline Externos & 1 & 2 & Externos & $1 / 1,5=0,6667$ & $2 / 3=0,6667$ \\
\hline Internos & $1 / 2$ & 1 & Internos & $0,5 / 1,5=0,3333$ & $1 / 3=0,3333$ \\
\hline SOMA & 1,5 & 3 & SOMA & 1 & 1 \\
\hline
\end{tabular}

Fonte: Elaboração Própria

Em seguida (tabela 6) é necessário calcular a média de cada uma das linhas da matriz normalizada de forma a gerar um vetor representando um dado item da estrutura, conforme a figura 10 .

Tabela 6 - Exemplo de média e vetor

\begin{tabular}{|c|c|c|c|}
\cline { 2 - 3 } Objetivo & Externos & Internos & MÉDIA \\
\hline Externos & 0,6667 & 0,6667 & 0,6667 \\
\hline Internos & 0,3333 & 0,3333 & 0,3333 \\
\hline SOMA & 1 & 1
\end{tabular}

Fonte: Elaboração Própria

A partir desses vetores se chega a uma nova matriz (tabela 7) referente à prioridade de cada item de um determinado nível da hierarquia em relação aos itens do nível imediatamente superior. 
Tabela 7- Exemplo de matriz prioridade

\begin{tabular}{|c|c|c|c|c|}
\cline { 2 - 3 } Objetivo & Externos & Internos & MÉDIA & Objetivo \\
\hline Externos & 0,6667 & 0,6667 & 0,6667 \\
\hline Internos & 0,3333 & 0,3333 & 0,3333 \\
\hline
\end{tabular}

$\begin{array}{lllll}\text { SOMA } & 1 & 1\end{array}$

Fonte: Elaboração Própria

Após todas as "matrizes comparação" terem sido convertidas em "matrizes prioridade", deve se alocar os resultados das matrizes prioridade na estrutura previamente definida (Figura 10). No exemplo da figura 11 abaixo, o critério de divisão $B 1$ tem um peso relativo de 0,3333 em relação ao objetivo $A 1$. Por sua vez, o critério subjetivo $C 1$ tem peso 0,7021 em relação ao critério de divisão $B 1$ e a variável $\mathrm{D} 1$ tem peso 0,4658 em relação ao critério subjetivo $\mathrm{C} 1$. Em outras palavras, B1 representa $33,3 \%$ do peso de $A 1, C 1$ representa $70,21 \%$ de $B 1$ e D1 representa $46,58 \%$ de $\mathrm{C} 1$.

Figura 11- Exemplo de alocação dos pesos relativos na estrutura

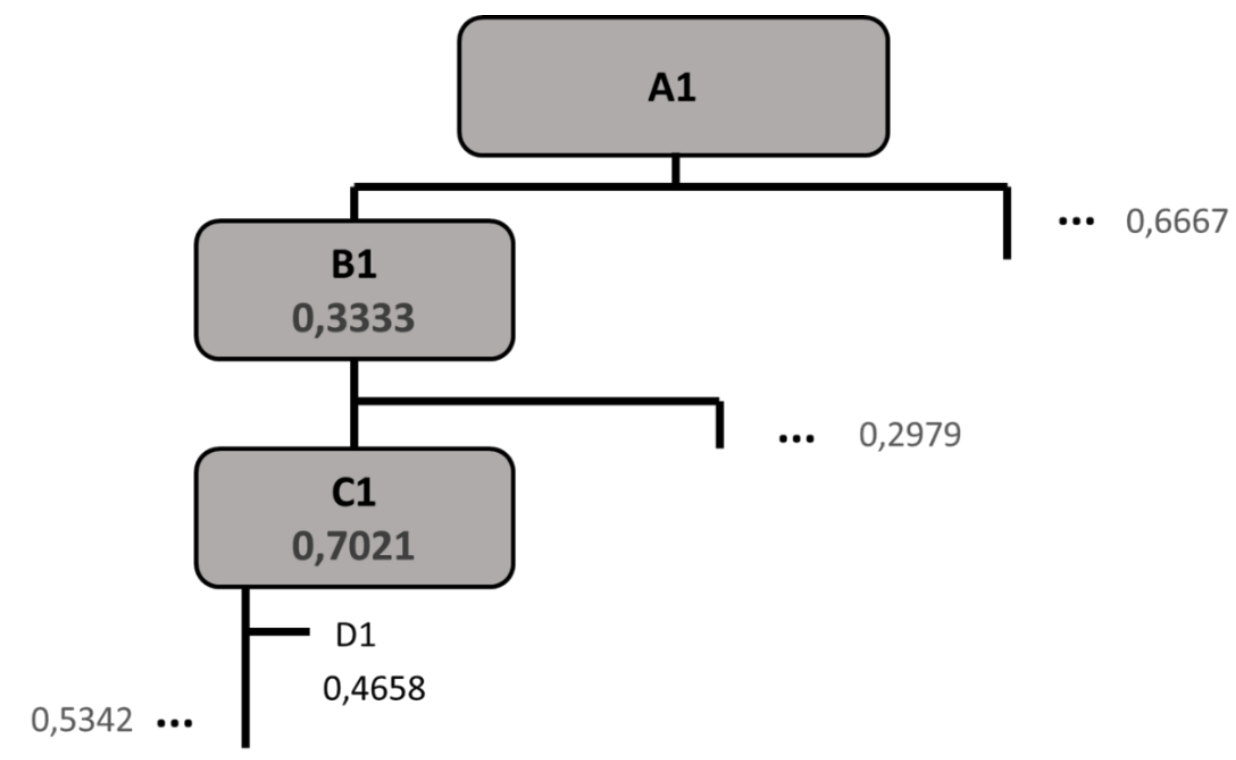

Fonte: Elaboração Própria

Para chegar no resultado final dos pesos relativos de cada uma das características em relação à avaliação dos imóveis, objetivo do método, é necessário multiplicar o peso de cada hierarquia com a imediatamente acima, começando pelo nível superior. Dessa forma, o resultado final será composto pela multiplicação dos elementos das matrizes prioridade. Considerando os dados da 
figura acima, o procedimento é multiplicar a representação (peso) de B1 $(0,3333)$ pela representação (peso) de C1 $(0,7021)$ e, finalmente, com a representação (peso) de D1 (0,4658): 0,3333 x 0,7021 x 0,4658 = 0,1090. Este representa a prioridade de $\mathrm{D} 1$ em relação ao critério $\mathrm{C} 1$, conforme a figura 12.

Figura 12 - Exemplo de fluxo de multiplicação de matrizes prioridade

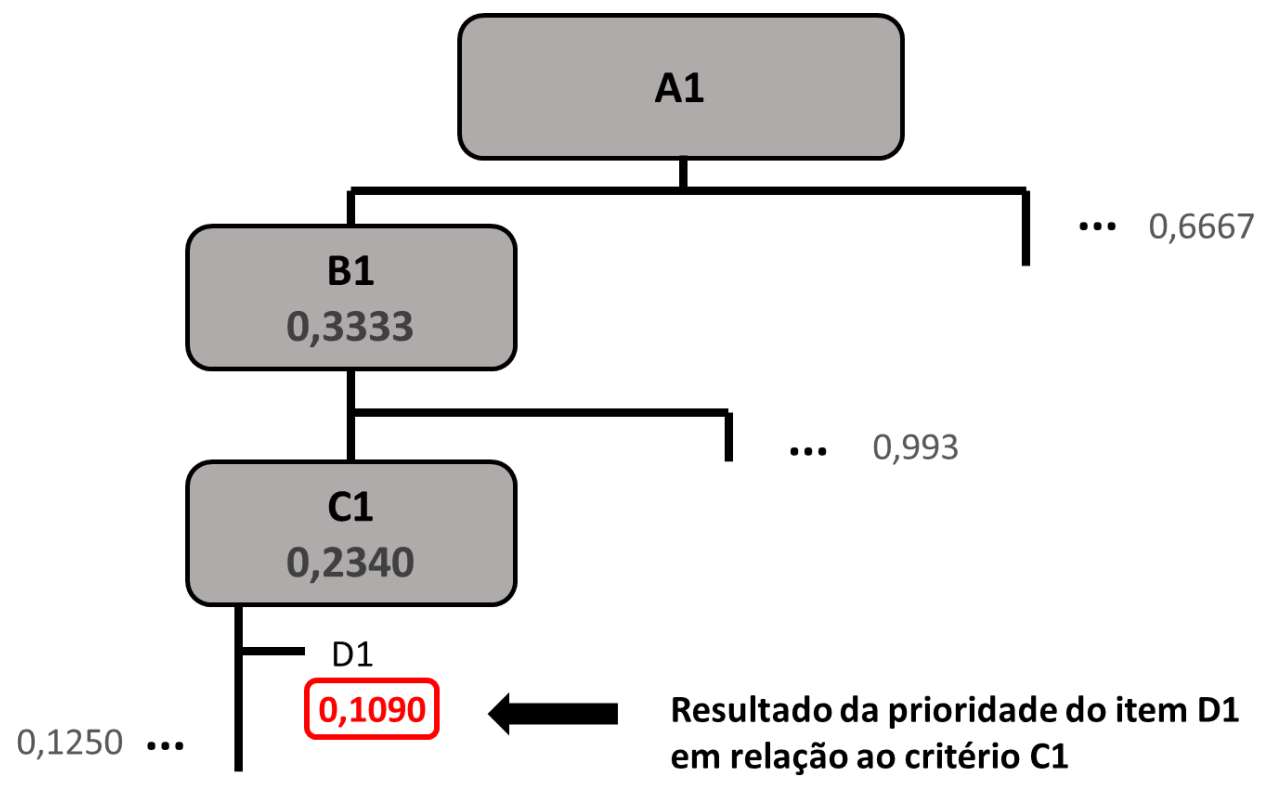

Fonte: Elaboração Própria

Caso uma determinada característica possua mais do que um critério imediatamente superior, para chegar ao resultado final da prioridade desta característica é necessário somar o resultado de sua prioridade em cada um dos critérios.

Figura 13 - Exemplo de resultado final

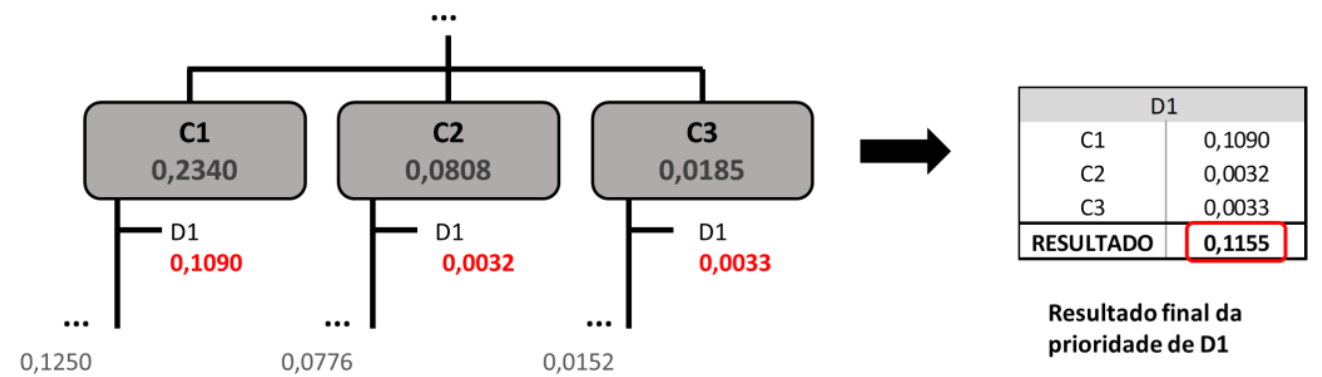

Fonte: Elaboração Própria 
Neste caso, o peso final da variável D1 para o objetivo da estrutura é igual a 0,1155, sendo que sobre C1 representa 0,0032, sobre C2 representa 0,1090 e sobre C3, 0,0033.

A partir do resultado final do nível hierárquico mais baixo é possível realizar uma hierarquia na qual os resultados indicam um maior ou menor índice de importância para o objetivo inicial, gerando assim objetividade e uma hierarquia para a comparação entre as alternativas (variáveis).

\subsection{Limitações do Método}

Apesar do método trazer uma série de vantagens para pesquisas com temas mais subjetivos, ou que envolvam decisões complexas, há algumas limitações para sua aplicação.

Apesar de criar certo nível de objetividade para problemas subjetivos, o método não está completamente isento de subjetividade. A definição dos critérios que compõem o objetivo e a definição da estrutura ainda possuem um caráter subjetivo, uma vez que indivíduos diferentes poderiam elencar critérios e estruturas diferentes.

Por exemplo, conforme será visto mais adiante, em ambos os grupos de foco foi percebida uma dificuldade inicial de compreensão da escala utilizada, uma vez que não existem pontos negativos em relação às comparações. Isso é, o nível mais baixo da escala de Saaty representa a igualdade em relação à variável de comparação. O "ponto neutro" é o menor valor da escala, diferente dos conceitos de escala mais utilizadas, onde o ponto neutro costuma ser a posição central. Isso acaba dificultando a aplicação do modelo sem a presença do pesquisador.

Devido ao fato do método usar a comparação par a par, o número de critérios ou características que podem ser observadas se torna limitado, uma vez que o número de comparações tende a crescer rapidamente conforme o número de itens a serem comparados.

Por depender de um consenso no momento de comparação entre dois itens, o modelo se torna mais difícil de se aplicar conforme aumentam o número 
de pessoas no grupo de foco, o que por sua vez acaba limitando o tamanho da amostra. Essa limitação, por sua vez, acaba causando uma dificuldade para se ter uma maior representatividade do universo de interesse. 


\section{Pesquisa de Campo}

\subsection{Fase de Pré-Testes}

Antes de realizar os experimentos, foram realizados pré-testes com consumidores para verificar se as imagens utilizadas durante a pesquisa (apêndice A) eram suficientemente representativas das características que retratavam. Para isso as imagens em 3D foram apresentadas (sem nenhum tipo de identificação) para pessoas selecionadas aleatoriamente e foi pedido que elas tentassem identificar o que cada imagem representava. Após considerações feitas neste estágio foram realizadas modificações com o intuito de torná-las mais adequadas a seu propósito. Após o terceiro teste, todas as imagens foram identificadas sem maiores dificuldades e assim foram consideradas satisfatórias para a utilização na pesquisa de campo.

Em seguida foram realizados testes para verificar a melhor forma de coletar os dados. Para isso foi desenvolvido um questionário para aplicação online. Foi pedido que os respondentes dessem um feedback em relação à sua experiência no processo de pesquisa. Porém, foi percebido que as pessoas tiveram grande dificuldade em respondê-la, devido às diferenças do método e da escala em relação aos modelos comumente utilizados.

Enquanto a escala proposta por Saaty varia da igualdade (nível zero) à extrema diferença (nível nove), as escalas de classificação mais populares tendem a colocar os extremos em cada ponta. Isso faz com que os respondentes confundissem a variável zero com "muito inferior", a variável nove com "muito superior" e aplicassem a igualdade no meio da escala (níveis quatro e cinco).

Por esse motivo foi realizada uma nova rodada de teste onde foi simulado um grupo de foco junto a um respondente de forma a estimular a discussão. Após ajustes feitos ao longo dos testes foi possível perceber a maior compreensão do modelo por parte dos respondentes e por esse motivo foi decidido seguir com esse formato. 
Uma vez finalizados os testes com um resultado satisfatório, a pesquisa foi realizada separadamente com cada um dos grupos de foco anteriormente mencionados: consumidores em geral e profissionais do ramo imobiliário.

\subsection{Validação dos Elementos}

Antes de iniciar as comparações das imagens, foram realizados debates em ambos os grupos de foco pedindo para que eles definissem características que consideram mais importantes quando da escolha de uma loja em momentos de consumo, e quais os critérios que eles utilizariam para julgar essas características. O intuito foi comparar a opinião dos entrevistados com as características e critérios previamente definidos como forma de validá-los.

Em relação aos critérios levantados, o grupo de consumidores elencou "estética" e "conforto" como formas de comparar as características do imóvel, enquanto o grupo do setor imobiliário listou "visibilidade" e "comodidade" (que pode ser considerado análogo a conforto). Ao levar em conta as respostas de ambos os grupos é possível perceber que os critérios elencados correspondem aos pré-definidos com base na bibliografia e entrevistas exploratórias: estética, visibilidade e conforto.

Em relação às características mencionadas durante os debates, houveram algumas divergências em relação às que haviam sido definidas previamente. Alguns dos consumidores elencaram aspectos sensoriais que não faziam parte dos aspectos construtivos ou de organização interna da loja, como odores e sons. Contudo, mencionaram infiltração e sujeira, ambos contidos na característica de conservação. Já o grupo de respondentes do setor imobiliário contribuiu ao citar o "pé-direito das lojas". Porém, após algum tempo de discussão chegaram à conclusão de que os demais fatores pré-selecionados eram mais importantes.

\subsection{Comparações dos Elementos}

Uma vez terminada a fase de validação foi realizada a etapa de comparação dos elementos, através do modelo par a par, levando em consideração os critérios selecionados. 
A primeira comparação realizada foi referente à importância dos subgrupos de conjuntos internos e externos em relação ao objetivo: elencar a característica de maior impacto para a percepção dos consumidores das lojas de varejo pelos participantes dos dois grupos focais.

Tabela 8 - Comparações dos subgrupos

\begin{tabular}{|c|c|c|c|c|c|c|c|}
\hline \multicolumn{8}{|c|}{ Objetivo } \\
\hline \multicolumn{4}{|c|}{ Consumidores } & \multicolumn{4}{|c|}{$\underline{\text { Mercado }}$} \\
\hline Externos & $X$ & 2 & Internos & Externos & 2 & $x$ & Internos \\
\hline
\end{tabular}

Fonte: Elaboração Própria

Pela tabela 8 é possível perceber que os consumidores deram maior importância aos fatores internos e os representantes do mercado imobiliário para os externos, embora de forma discreta (nível 2 da escala de Saaty). Este resultado já era esperado, uma vez que os internos têm maior influência sobre a experiência de compra, enquanto os externos são compostos por aspectos mais técnicos e "imutáveis" do imóvel.

Em seguida foi realizada a comparação da importância relativa dos diferentes critérios dentro de cada um dos subgrupos mencionados anteriormente, uma vez que determinado critério pode ter um peso diferente, dependendo se o respondente o analisa em função dos aspectos externos ou internos do imóvel.

Tabela 9 - Comparações dos critérios no subgrupo externos

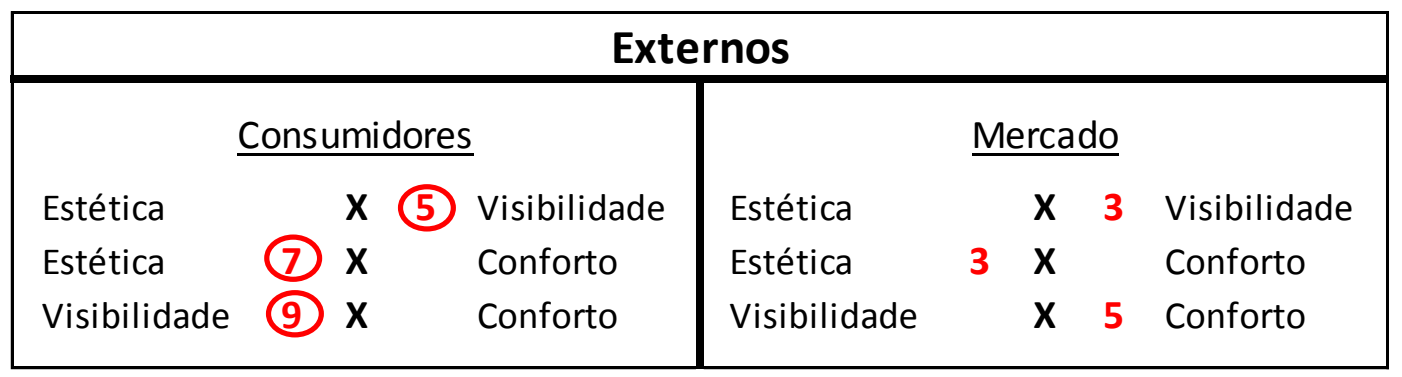

Fonte: Elaboração Própria 
Ambos os grupos de foco expressaram as mesmas prioridades em relação aos elementos durante as comparações dos critérios sobre 0 subconjunto de aspectos externos. Porém, o grupo referente aos consumidores demonstrou uma maior percepção da diferença de importância entre os critérios do que o grupo de especialistas do setor imobiliário. Observa-se que os níveis da escala utilizados pelos participantes consumidores foram superiores àqueles usados pelos profissionais do mercado. Enquanto o primeiro grupo variou de 5 a 9 pontos (importância forte a importância extrema), o segundo variou de 3 a 5 (importância moderada a forte).

Tabela 10 - Comparações dos critérios no subgrupo internos

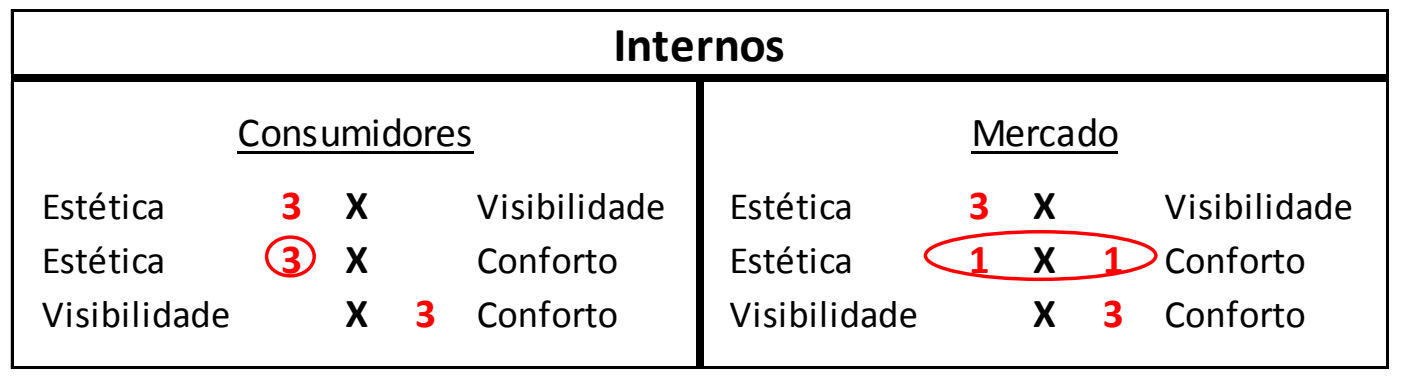

Fonte: Elaboração Própria

Ao confrontar os resultados das comparações dos critérios dentro dos subconjuntos de elementos externos e internos é possível perceber que há uma diferença na escala utilizada para expressar a importância de cada elemento, assim como uma inversão de preferência em dois critérios (estética x conforto). Isso demonstra que a relação de importância dos critérios se altera, dependendo do subconjunto analisado.

O último grupo de comparações a ser realizada diz respeito à importância relativa de cada uma das características, dentro de seus respectivos subgrupos, em relação aos critérios (estética, visibilidade e conforto), conforme a seguir. 
Tabela 11 - Comparações das características para o critério estética (externo)

\begin{tabular}{|c|c|c|c|c|c|c|c|c|}
\hline \multicolumn{9}{|c|}{ Estética (Externo) } \\
\hline \multicolumn{4}{|c|}{ Consumidores } & \multicolumn{5}{|c|}{ Mercado } \\
\hline Esquina & $\mathbf{x}$ & 6 & Recuo & Esquina & 7 & $\mathbf{x}$ & & Recuo \\
\hline Esquina & $x$ & 7 & Testada & Esquina & 3 & $x$ & & Testada \\
\hline Esquina & $x$ & 9 & Transparência & Esquina & 1 & $\mathbf{X}$ & 1) & Transparência \\
\hline Recuo & $\mathbf{x}$ & 3 & Testada & Recuo & & $\mathbf{x}$ & 3 & Testada \\
\hline Recuo & $x$ & 7 & Transparência & Recuo & & $x$ & 5 & Transparência \\
\hline Testada & $x$ & 3 & Transparência & Testada & & $x$ & 3 & Transparência \\
\hline
\end{tabular}

Fonte: Elaboração Própria

As maiores diferenças encontradas entre as respostas dos grupos focos, em relação ao critério de estética no subgrupo de características externas, dizem respeito à importância da característica esquina. Enquanto o grupo representado pelos consumidores considerou esta característica como a menos importante, o grupo composto por especialistas do mercado considerou-a como a mais importante. Marcante ainda a classificação da variável transparência frente à variável esquina pelo grupo de consumidores, atribuindo a esta o maior nível da escala, enquanto o grupo dos profissionais do setor imobiliário as classificaram como equivalentes em nível de importância.

Tabela 12 - Comparações das características para o critério visibilidade (externo)

\begin{tabular}{|c|c|c|c|c|c|c|c|}
\hline \multicolumn{8}{|c|}{ Visibilidade (Externo) } \\
\hline \multicolumn{4}{|c|}{ Consumidores } & \multicolumn{4}{|c|}{ Mercado } \\
\hline Esquina & 9 & $x$ & Recuo & Esquina & 9 & $x$ & Recuo \\
\hline Esquina & 7 & $\mathbf{x}$ & Testada & Esquina & 5 & $\mathbf{x}$ & Testada \\
\hline Esquina & (1) & $x$ & Transparência & Esquina & (7) & $x$ & Transparência \\
\hline Recuo & & $\times 7$ & Testada & Recuo & & $\times 7$ & Testada \\
\hline Recuo & & $x$ (9) & Transparência & Recuo & & $x$ (5) & Transparência \\
\hline Testada & & $x$ (2) & Transparência & Testada & (3) & $x$ & Transparência \\
\hline
\end{tabular}

Fonte: Elaboração Própria

No quesito visibilidade, no subgrupo de características externas, os resultados foram muito semelhantes, tendo como principais diferenças a comparação entre testada e transparência e, em menor grau, esquina. O grupo 
focal representando os consumidores justificaram a escolha da transparência como mais importante, argumentando que esta característica permite que os produtos sejam melhores expostos e por isso chamam mais atenção. Porém, o grupo dos profissionais do setor imobiliário afirma que uma maior testada aumenta a área de exposição de uma loja, tornando-a mais visível.

Tabela 13 - Comparações das características para o critério conforto (externo)

\begin{tabular}{|c|c|c|c|c|c|c|c|c|c|}
\hline \multicolumn{10}{|c|}{ Conforto (Externo) } \\
\hline \multicolumn{5}{|c|}{ Consumidores } & \multicolumn{5}{|c|}{ Mercado } \\
\hline Esquina & & $x$ & 3 & Recuo & Esquina & & $x$ & 3 & Recuo \\
\hline Esquina & & $x$ & 3 & Testada & Esquina & & $\mathbf{x}$ & 3 & Testada \\
\hline Esquina & 3 & $x$ & & Transparência & Esquina & 3 & $x$ & & Transparência \\
\hline Recuo & & $\mathbf{x}$ & (3) & Testada & Recuo & 1 & $x$ & 1 & Testada \\
\hline Recuo & 3 & $x$ & & Transparência & Recuo & 2 & $x$ & & Transparência \\
\hline Testada & 1 & $x$ & 1 & Transparência & Testada & (3) & $x$ & & Transparência \\
\hline
\end{tabular}

Fonte: Elaboração Própria

Quando perguntados sobre a importância de cada uma das características externas em relação ao critério de conforto, ambos os grupos utilizaram números baixos dentro da escala de Saaty. Este resultado indica que os dois grupos acreditam que há pouca diferença entre o impacto das características externas na percepção de conforto.

Contudo, pequenas discrepâncias são observadas entre os grupos focais no que tange suas avaliações sobre as características testada, recuo e transparência. Enquanto os profissionais do setor imobiliário veem equidade entre recuo e testada, os consumidores atribuem maior importância à testada. $O$ oposto se observa em relação às variáveis testada e transparência, onde é o segundo grupo que atribui maior importância à testada. 
Tabela 14 - Comparações das características para o critério estética (interno)

\begin{tabular}{|c|c|c|c|c|c|c|c|}
\hline \multicolumn{8}{|c|}{ Estética (Interno) } \\
\hline \multicolumn{4}{|c|}{$\underline{\text { Consumidores }}$} & \multicolumn{4}{|c|}{ Mercado } \\
\hline Conservação & 7 & $\mathrm{x}$ & Cores & Conservação & 5 & $x$ & Cores \\
\hline Conservação & & $x$ (3) & Iluminação & Conservação & (3) & $x$ & Iluminação \\
\hline Conservação & 5 & $\mathrm{x}$ & Circulação & Conservação & 5 & $\mathrm{x}$ & Circulação \\
\hline Cores & & $x(7)$ & Iluminação & Cores & & $x$ (3) & Iluminação \\
\hline Cores & (5) & $\mathbf{x}$ & Circulação & Cores & (2) & $x$ & Circulação \\
\hline Iluminação & (6) & $x$ & Circulação & Iluminação & & $x$ (3) & Circulação \\
\hline
\end{tabular}

Fonte: Elaboração Própria

Ao contrastar as comparações das características internas em relação ao critério estética, é possível perceber que o segundo grupo deu uma importância menor para a característica de iluminação e maior para circulação, enquanto o primeiro classificou com maior intensidade a iluminação. Dessa forma, os resultados acabaram ficando menos polarizados do que os do outro grupo, onde há um claro domínio das características relativas à conservação e iluminação.

Tabela 15 - Comparações das características para o critério visibilidade (interno)

\begin{tabular}{|c|c|c|c|c|c|c|c|c|c|}
\hline \multicolumn{10}{|c|}{ Visibilidade (Interno) } \\
\hline \multicolumn{5}{|c|}{$\underline{\text { Consumidores }}$} & \multicolumn{5}{|c|}{ Mercado } \\
\hline Conservação & & $\mathbf{x}$ & 3 & Cores & Conservação & & $\mathbf{x}$ & 3 & Cores \\
\hline Conservação & & $x$ & 5 & Iluminação & Conservação & & $x$ & 5 & Iluminação \\
\hline Conservação & 3 & $x$ & & Circulação & Conservação & 3 & $x$ & & Circulação \\
\hline Cores & & $\mathbf{x}$ & (7) & Iluminação & Cores & & $x$ & (3) & Iluminação \\
\hline Cores & $(7)$ & $x$ & & Circulação & Cores & $(3)$ & $x$ & & Circulação \\
\hline Iluminação & 9 & $\mathbf{x}$ & & Circulação & Iluminação & 5 & $\mathbf{x}$ & & Circulação \\
\hline
\end{tabular}

Fonte: Elaboração Própria

Ao comparar as características internas em relação ao aspecto de visibilidade, ambos os grupos expressaram as mesmas preferências nas comparações dos critérios. A distinção entre os resultados se encontra, principalmente, nos pesos dados aos critérios de circulação, iluminação e cores. O grupo representado por especialistas de mercado considerou como de maior importância a iluminação, embora com nível menor do que o representado pelos 
consumidores. Os consumidores também classificaram as cores de maneira mais acentuada do que os profissionais do mercado.

Tabela 16 - Comparações das características para o critério conforto (interno)

\begin{tabular}{|c|c|c|c|c|c|c|c|}
\hline \multicolumn{8}{|c|}{ Conforto (Interno) } \\
\hline \multicolumn{5}{|c|}{ Consumidores } & \multicolumn{3}{|c|}{ Mercado } \\
\hline Conservação & 5 & $x$ & & Cores & Conservação 9 & $\mathrm{r}$ & Cores \\
\hline Conservação & & $x$ & (2) & Iluminação & Conservação (3) & r & Iluminação \\
\hline Conservação & (8) & $x$ & & Circulação & Conservação 3 & r & Circulação \\
\hline Cores & & $x$ & 3 & Iluminação & Cores & $x 6$ & Iluminação \\
\hline Cores & & $x$ & 3 & Circulação & Cores & $x(7)$ & Circulação \\
\hline Iluminação & (2) & $x$ & & Circulação & Iluminação 1 & $\begin{array}{l}x \quad 1 \\
\end{array}$ & Circulação \\
\hline
\end{tabular}

Fonte: Elaboração Própria

Quando consideradas as comparações das características internas em relação ao critério de conforto, é possível perceber que ambos os grupos acreditam que o aspecto de cores possuí pouca importância. Porém, os grupos divergem em relação aos critérios circulação, conservação e iluminação, seja na prioridade, seja na intensidade de seu peso. O grupo representando por consumidores julga circulação como menos importante, em oposição ao grupo composto por especialistas do mercado imobiliário, que avaliaram mais intensamente a conservação.

\subsection{Resultados da Estrutura}

Após terem sido realizadas todas as comparações e aplicado o tratamento de dados (Apêndice B), conforme descrito no capítulo 3, foi obtida uma estrutura hierárquica final, para cada um dos grupos focos observados, com os valores de prioridade para cada uma das características em relação à questão estudada: influência das variáveis do imóvel e de seu ambiente físico nas percepções dos consumidores sobre lojas de varejo. 
Figura 14 - Estrutura de prioridades (consumidores)

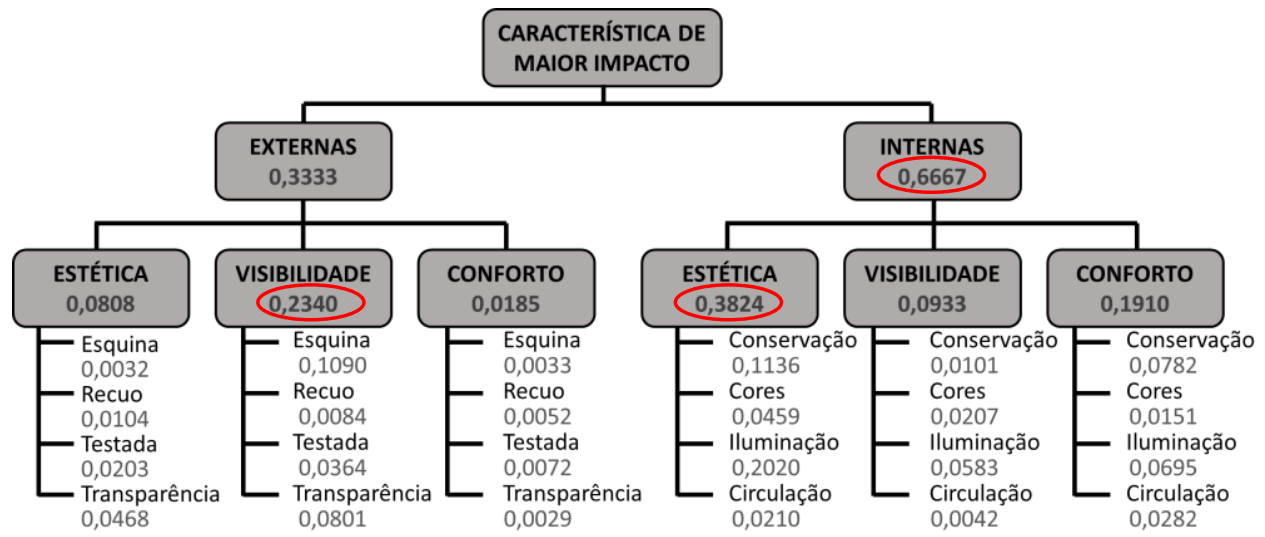

Fonte: Elaboração Própria

Ao realizar uma análise de forma mais estruturada das prioridades do grupo representado pelos consumidores, é possível perceber que os dois critérios que eles acreditam ter maior impacto na percepção do consumidor de lojas de varejo seriam a estética em relação às características internas, especialmente a iluminação e conservação, e a visibilidade em relação às características externas, com ênfase nas características transparência e esquina.

Figura 15 - Estrutura de prioridades (mercado)

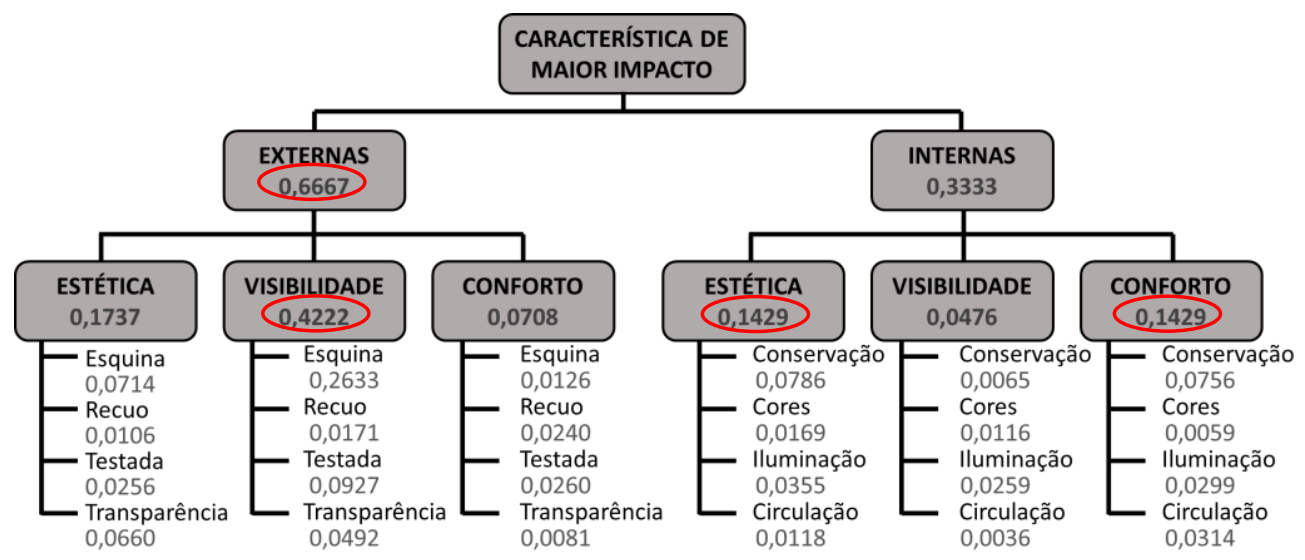

Fonte: Elaboração Própria

O grupo composto por especialistas do mercado imobiliário classificou 0 critério de visibilidade em relação às características externas, com foco marcante na esquina, como o principal critério para impacto na percepção do consumidor das lojas de varejo de rua. Além disso, eles consideram os critérios de estética e 
conforto relativos às características internas igualmente importantes, em especial a característica de conservação.

Conforme descrito anteriormente no capítulo 3, para que possa identificar uma hierarquia de características em relação ao objetivo principal da pesquisa, é necessário somar os resultados deprioridade das características para cada um dos critérios imediatamente acima.

Tabela 17 - Resultado Final (consumidores)

\begin{tabular}{|c|c|}
\hline \multicolumn{2}{|c|}{ Esquina } \\
Estética & 0,0032 \\
Visibilidade & 0,1090 \\
Conforto & 0,0033 \\
\hline RESULTADO & $\mathbf{0 , 1 1 5 5}$ \\
\hline
\end{tabular}

\begin{tabular}{|c|c|}
\hline \multicolumn{2}{|c|}{ Recuo } \\
Estética & 0,0104 \\
Visibilidade & 0,0084 \\
Conforto & 0,0052 \\
\hline RESULTADO & $\mathbf{0 , 0 2 4 1}$ \\
\hline
\end{tabular}

\begin{tabular}{|c|c|}
\hline \multicolumn{2}{|c|}{ Testada } \\
Estética & 0,0203 \\
Visibilidade & 0,0364 \\
Conforto & 0,0072 \\
\hline RESULTADO & $\mathbf{0 , 0 6 3 9}$ \\
\hline
\end{tabular}

\begin{tabular}{|c|c|}
\hline \multicolumn{2}{|c|}{ Transparência } \\
Estética & 0,0468 \\
Visibilidade & 0,0801 \\
Conforto & 0,0029 \\
\hline RESULTADO & $\mathbf{0 , 1 2 9 8}$ \\
\hline
\end{tabular}

\begin{tabular}{|c|c|}
\hline \multicolumn{2}{|c|}{ Conservação } \\
Estética & 0,1136 \\
Visibilidade & 0,0101 \\
Conforto & 0,0782 \\
\hline RESULTADO & $\mathbf{0 , 2 0 1 9}$ \\
\hline
\end{tabular}

\begin{tabular}{|c|c|}
\hline \multicolumn{2}{|c|}{ Cores } \\
Estética & 0,0459 \\
Visibilidade & 0,0207 \\
Conforto & 0,0151 \\
\hline RESULTADO & $\mathbf{0 , 0 8 1 6}$ \\
\hline
\end{tabular}

\begin{tabular}{|c|c|}
\hline \multicolumn{2}{|c|}{ Iluminação } \\
Estética & 0,2020 \\
Visibilidade & 0,0583 \\
Conforto & 0,0695 \\
\hline RESULTADO & $\mathbf{0 , 3 2 9 8}$ \\
\hline
\end{tabular}

\begin{tabular}{|c|c|}
\hline \multicolumn{2}{|c|}{ Circulação } \\
Estética & 0,0210 \\
Visibilidade & 0,0042 \\
Conforto & 0,0282 \\
\hline RESULTADO & $\mathbf{0 , 0 5 3 3}$ \\
\hline
\end{tabular}

Fonte: Elaboração Própria

O mesmo processo foi realizado para o grupo de profissionais do mercado imobiliário, com o intuito de gerar uma hierarquia comparativa. Dessa forma é possível comparar as discrepâncias entre a opinião dos especialistas do setor com a do público consumidor.

Tabela 18 - Resultado Final (mercado)

\begin{tabular}{|c|c|}
\hline \multicolumn{2}{|c|}{ Esquina } \\
C1 & 0,0714 \\
C2 & 0,2633 \\
C3 & 0,0126 \\
\hline RESULTADO & $\mathbf{0 , 3 4 7 3}$ \\
\hline
\end{tabular}

\begin{tabular}{|c|c|}
\hline \multicolumn{2}{|c|}{ Conservação } \\
C4 & 0,0786 \\
C5 & 0,0065 \\
C6 & 0,0756 \\
\hline RESULTADO & $\mathbf{0 , 1 6 0 7}$ \\
\hline
\end{tabular}

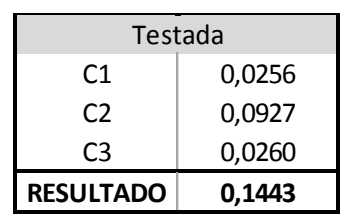

\begin{tabular}{|c|c|}
\hline \multicolumn{2}{|c|}{ lluminação } \\
C4 & 0,0355 \\
C5 & 0,0259 \\
C6 & 0,0299 \\
\hline RESULTADO & $\mathbf{0 , 0 9 1 3}$ \\
\hline
\end{tabular}

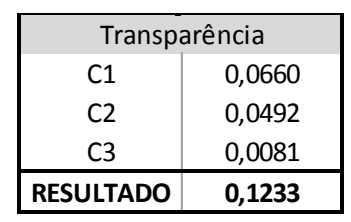

\begin{tabular}{|c|c|}
\hline \multicolumn{2}{|c|}{ Circulação } \\
C4 & 0,0118 \\
C5 & 0,0036 \\
C6 & 0,0314 \\
\hline RESULTADO & $\mathbf{0 , 0 4 6 9}$ \\
\hline
\end{tabular}

Fonte: Elaboração Própria 


\subsection{Tabelas de Hierarquia}

A partir dos resultados obtidos na etapa anterior, é possível determinar, para ambos os grupos estudados, a hierarquia do impacto das características do ambiente físico estudadas na percepção do consumidor de lojas do varejo. Para melhor visualização dos resultados foram confeccionadas tabelas com as características ranqueadas e ordenadas de acordo com o valor da prioridade obtida na pesquisa.

Tabela 19 - Hierarquia das características do ambiente físico

CONSUMIDORES

\begin{tabular}{|ccc|}
\hline \multicolumn{3}{|c|}{ Hierarquia Total } \\
Rank & ASPECTO & VALOR \\
\hline 1 & Iluminação & 0,3298 \\
\hline 2 & Conservação & 0,2019 \\
\hline 3 & Transparência & 0,1298 \\
\hline 4 & Esquina & 0,1155 \\
\hline 5 & Cores & 0,0816 \\
\hline 6 & Testada & 0,0639 \\
\hline 7 & Circulação & 0,0533 \\
\hline 8 & Recuo & 0,0241 \\
\hline
\end{tabular}

SETOR IMOBILIÁRIO

\begin{tabular}{|ccc|}
\hline \multicolumn{3}{|c|}{ Hierarquia Total } \\
Rank & ASPECTO & VALOR \\
\hline 1 & Esquina & 0,3473 \\
\hline 2 & Conservação & 0,1607 \\
\hline 3 & Testada & 0,1443 \\
\hline 4 & Transparência & 0,1233 \\
\hline 5 & Iluminação & 0,0913 \\
\hline 6 & Recuo & 0,0517 \\
\hline 7 & Circulação & 0,0469 \\
\hline 8 & Cores & 0,0345 \\
\hline
\end{tabular}

Fonte: Elaboração Própria

Através da comparação entre os resultados obtidos entre os dois grupos de foco é possível perceber que a maior diferença está no peso que cada grupo deu para os fatores externos, aspectos construtivos ou de implantação do imóvel, e internos, relativos ao uso pela marca e conservação. Isso provavelmente se deve ao fato do setor imobiliário costumar se concentrar mais nos fatores construtivos dos imóveis, devido ao alto custo de alteração, enquanto o consumidor costuma estar mais concentrado na experiência de compra em si, que ocorre dentro da loja.

Porém, ao se observar os quatro aspectos mais importantes, ambos os grupos elencaram conservação, transparência e esquina, apesar de em ordens diferentes. Isso indica que existe um consenso entre os grupos em relação ao alto nível de importância dessas características. 
Da mesma forma como é possível criar uma tabela com a hierarquia das características do ambiente físico em relação ao impacto nos padrões de consumo do varejo, também é possível decompor esse resultado criando tabelas com a hierarquia das características para cada um dos critérios de comparação.

Tabela 20 - Hierarquia estética

\section{CONSUMIDORES}

0,4632

\begin{tabular}{|ccc|}
\hline \multicolumn{3}{|c|}{ Hierarquia Estética } \\
Rank & ASPECTO & VALOR \\
\hline 1 & Iluminação & 0,2020 \\
\hline 2 & Conservação & 0,1136 \\
\hline 3 & Transparência & 0,0468 \\
\hline 4 & Cores & 0,0459 \\
\hline 5 & Circulação & 0,0210 \\
\hline 6 & Testada & 0,0203 \\
\hline 7 & Recuo & 0,0104 \\
\hline 8 & Esquina & 0,0032 \\
\hline
\end{tabular}

SETOR IMOBILIÁRIO

0,3165

\begin{tabular}{|ccc|}
\hline \multicolumn{3}{|c|}{ Hierarquia Estética } \\
Rank & ASPECTO & VALOR \\
\hline 1 & Conservação & 0,0786 \\
\hline 2 & Esquina & 0,0714 \\
\hline 3 & Transparência & 0,0660 \\
\hline 4 & Iluminação & 0,0355 \\
\hline 5 & Testada & 0,0256 \\
\hline 6 & Cores & 0,0169 \\
\hline 7 & Circulação & 0,0118 \\
\hline 8 & Recuo & 0,0106 \\
\hline
\end{tabular}

Fonte: Elaboração Própria

Para os consumidores, o conceito de estética está mais voltado às características internas de uma loja, isso pode ser percebido pelo fato dessas características ocuparem quatro dos cinco ranques mais altos da tabela.

Tabela 21 - Hierarquia visibilidade

\section{CONSUMIDORES}

\begin{tabular}{|ccc|}
\hline \multicolumn{3}{|c|}{ Hierarquia Visibilidade } \\
\hline Rank & ASPECTO & VALOR \\
\hline 1 & Esquina & 0,1090 \\
\hline 2 & Transparência & 0,0801 \\
\hline 3 & Iluminação & 0,0583 \\
\hline 4 & Testada & 0,0364 \\
\hline 5 & Cores & 0,0207 \\
\hline 6 & Conservação & 0,0101 \\
\hline 7 & Recuo & 0,0084 \\
\hline 8 & Circulação & 0,0042 \\
\hline
\end{tabular}

SETOR IMOBILIÁRIO 0,4698

\begin{tabular}{|ccc|}
\hline \multicolumn{3}{|c|}{ Hierarquia Visibilidade } \\
Rank & ASPECTO & VALOR \\
\hline 1 & Esquina & 0,2633 \\
\hline 2 & Testada & 0,0927 \\
\hline 3 & Transparência & 0,0492 \\
\hline 4 & Iluminação & 0,0259 \\
\hline 5 & Recuo & 0,0171 \\
\hline 6 & Cores & 0,0116 \\
\hline 7 & Conservação & 0,0065 \\
\hline 8 & Circulação & 0,0036 \\
\hline
\end{tabular}

Fonte: Elaboração Própria 
Ambos os grupos parecem concordar que o critério de visibilidade está mais relacionado às características externas da loja, já que nos dois casos esquina, transparência e testada estavam presentes entre os quatro fatores de maior relevância. Além disso, os grupos demonstraram um consenso em relação ao fato do aspecto mais importante para visibilidade ser a esquina.

É possível perceber que os pesos dos critérios de visibilidade e estética estão basicamente invertidos entre os dois grupos. Durante a realização da pesquisa o grupo dos consumidores chamou atenção para o fato de que uma loja com alta visibilidade e baixa estética pode ter um efeito de repulsa no consumidor, justificando o maior peso para estética. No entanto, o grupo de mercado acha que visibilidade é mais importante, por ser mais difícil de se atingir, enquanto estética é mais facilmente alterada.

Tabela 22 - Hierarquia conforto

\section{CONSUMIDORES}

0,2095

\begin{tabular}{|ccc|}
\hline \multicolumn{3}{|c|}{ Hierarquia Conforto } \\
Rank & ASPECTO & VALOR \\
\hline 1 & Conservação & 0,0782 \\
\hline 2 & Iluminação & 0,0695 \\
\hline 3 & Circulação & 0,0282 \\
\hline 4 & Cores & 0,0151 \\
\hline 5 & Testada & 0,0072 \\
\hline 6 & Recuo & 0,0052 \\
\hline 7 & Esquina & 0,0033 \\
\hline 8 & Transparência & 0,0029 \\
\hline
\end{tabular}

Fonte: Elaboração Própria
SETOR IMOBILIÁRIO

0,2136

\begin{tabular}{|ccc|}
\hline \multicolumn{3}{|c|}{ Hierarquia Conforto } \\
Rank & ASPECTO & VALOR \\
\hline 1 & Conservação & 0,0756 \\
\hline 2 & Circulação & 0,0314 \\
\hline 3 & Iluminação & 0,0299 \\
\hline 4 & Testada & 0,0260 \\
\hline 5 & Recuo & 0,0240 \\
\hline 6 & Esquina & 0,0126 \\
\hline 7 & Transparência & 0,0081 \\
\hline 8 & Cores & 0,0059 \\
\hline
\end{tabular}

Em relação ao critério de conforto, não só o peso do critério em si como ambas as hierarquias dos dois grupos foram muito semelhantes. Os aspectos conservação, iluminação e circulação, características internas, foram considerados os três aspectos mais importantes para conforto. No caso dos consumidores, as características internas tiveram domínio sobre as externas nesse quesito, de forma que os quatro aspectos internos ocuparam os quatro maiores ranques. 


\section{Conclusão}

Após analisar os resultados foi possível perceber que existe uma dissonância entre a percepção dos especialistas do mercado imobiliário e os consumidores de varejo de forma geral. Isso se deve, especialmente, pela diferença de peso dado aos grupos de características internas e externas e aos critérios de visibilidade e estética, uma vez que as hierarquias decompostas em critérios possuem alta semelhança.

Dessa forma, é possível concluir que as características externas estão mais voltadas ao critério de visibilidade, altamente procurado no mercado, devido à sua dificuldade de alteração, enquanto estética e conforto estão mais vinculadas aos quesitos internos, apreciados pelos consumidores devido à sua participação na experiência de compra.

Tendo isso em mente, recomenda-se que ao realizar a busca de um imóvel comercial de varejo de rua, seja para locação ou compra para investimento, procurar por aqueles com alta visibilidade com características como localização em esquina e preferencialmente com testadas maiores, já que essas características se mostraram de grande importância e são imutáveis. Imóveis com maior transparência também são desejáveis, porém essa característica do imóvel é possível de ser alterada.

Já em relação às lojas consolidadas que procuram gerar um incremento de vendas através de um impacto mais positivo no padrão de consumo de seus consumidores, recomenda-se um maior foco em conforto e estética, através dos aspectos de conservação e iluminação, já que foram os dois aspectos mais bem avaliados pelos consumidores e podem ser alterados sem a necessidade de obras mais extensivas e o consequente custo. $O$ uso adequado de cores no espaço, apesar de não ter tido tanto destaque quanto os outros aspectos mencionados, também se mostrou muito importante para os consumidores e pode se mostrar uma forma de obter um diferencial na experiência de consumo. A transparência da fachada novamente se mostra um aspecto fundamental, mas 
devido à necessidade de obras mais extensas recomenda-se realiza-la apenas após considerar que os outros três aspectos mencionados estejam satisfatórios. 


\section{Referências Bibliográficas}

AMERICAN MARKETING ASSOCIATION. Definitions of marketing. Estados Unidos, 2017 Disponível em: <https://www.ama.org/the-definition-of-marketingwhat-is-marketing/>. Acessado em: 31 de outubro de 2019

ASSOCIAÇÃO BRASILEIRA DE NORMAS TÉCNICAS. NBR 14653-1: Avaliação de bens Parte 1: Procedimentos gerais. Rio de Janeiro, 2001.

ASSOCIAÇÃO BRASILEIRA DE NORMAS TÉCNICAS. NBR 14653-3: Avaliação de bens Parte 3: Imóveis Rurais. Rio de Janeiro, 2004.

ASSOCIAÇÃO BRASILEIRA DE NORMAS TÉCNICAS. NBR 14653-2: Avaliação de bens Parte 2: Imóveis Urbanos. Rio de Janeiro, 2011.

BAKER, Julie. The role of the environment marketing services: The consumer perspective. Texas, 1986. Dissertação (Doutorado em Marketing) Departamento de Administração: Texas Christian University.

BALASSIANO, Rodrigo. Saiba qual a relação entre queda de juros e Fundos Imobiliários (FII). EXAME, São Paulo, 28 de outubro de 2019. Disponível em: $<$ https://exame.abril.com.br/negocios/releases/saiba-qual-a-relacao-entre-quedade-juros-e-fundos-imobiliarios-fii-por-rodrigo-balassiano/>. Acesso em: 02 de novembro de 2019.

BANCO CENTRAL DO BRASIL. Taxas de juros básicas - Histórico. Brasil, 2019 Disponível em: < https://www.bcb.gov.br/controleinflacao/historicotaxasjuros >. Acesso em: 30 de outubro. 2019.

BERRY; Leonard L.; PARASURAMAN, A. Marketing Services: Competing through quality. New York: The Free Press, 2004. 
BRASIL. Institui o Código Civil. Diário Oficial da União: seção 1, Brasília, 10 de janeiro de 2002 Disponível em <http://www.planalto.gov.br/ccivil_03/leis/2002//10406.htm>. Acessado em: 31 de outubro de 2019.

COBRA, M. Administração de Marketing, 2 ed. São Paulo: Editora Atlas, 1992.

COMISSÂO TÉCNICA NACIONAL DE INVESTIMENTOS IMOBILIÁRIOS. GUIA DE MELHORES PRÁTICAS EM AVALIAÇÃO IMOBILIÁRIA. 1 ed. São Paulo: ABRAPP, 2016.

CUTAIT, Beatriz. Com ajustes nas expectativas para PIB e inflação, mercado projeta corte de 0,50 ponto da taxa Selic hoje. INFOMONEY, São Paulo, 30 de outubro de 2019. Disponível em: <https://www.infomoney.com.br/economia/comajustes-nas-expectativas-para-pib-e-inflacao-mercado-projeta-corte-de-050ponto-da-taxa-selic-hoje/>. Acesso em: 30 de outubro de 2019

DURÃO, Mariana. Mercado imobiliário do Rio de Janeiro começa a ver sinais de retomada. O Estado de S. Paulo, São Paulo, 13 de outubro de 2019. Disponível em: <https://economia.estadao.com.br/noticias/geral,mercado-imobiliario-do-riode-janeiro-comeca-a-ver-sinais-de-retomada,70003048689> Acessado em: 30 de outubro de 2019.

ENGEL, James F.; BLACKWELL, Roger D.; MINIARD, Paul W. Comportamento do Consumidor. 8 ed. São Paulo: Livros Técnicos e Científicos Ltda., 2000.

FRAGA, Robson. Administração de Marketing. 12 ed. São Paulo: Prentice Hall, 2006.

FROST, Everett L.; HOEBEL, E. Adamson. Antropologia cultural e social. Tradução de Euclides Carneiro da Silva. São Paulo: Cultrix, 2006.

FUTRELL, Charles M. Vendas: O guia completo. 12 ed. Porto Alegre: Bookman, 2014. 
GEARGEOURA, Lucien J.; PARENTE, Juracy. Ambiência da Loja e Estratégia Mercadológica no Varejo: Um Modelo Teórico Consolidado. São Paulo: XXXIII Encontro da EnANPAD, 2009.

I-SCOOP. Digital transformation in retail: transforming for the new commerce reality. Bélgica, 2016 Disponível em: < https://www.iscoop.eu/digital-transformation/retail-industry-digital-mobile-shoppingtransformation/>. Acesso em: 09 de junho. 2019.

KANT, Immanuel. Antropologia de um ponto de vista pragmático. Tradução de Clécia Aparecida Martins. São Paulo: lluminuras, 2006.

KOTLER, Philip. Administração de marketing: a edição do novo milênio. São Paulo: Prentice Hall, 2000.

LARGHI, Nathália. Se a Selic for a 4\% neste ano, o retorno da renda fixa pode virar perda. Prepare-se. Valor Investe, São Paulo, 21 de outubro de 2019. Disponível em: <https://valorinveste.globo.com/produtos/rendafixa/noticia/2019/10/21/se-a-selic-for-a-4percent-neste-ano-o-retorno-da-rendafixa-pode-virar-perda-prepare-se.ghtml>. Acesso em: 30 de outubro de 2019

LAS CASAS, Alexandre Luzzi. Marketing de varejo. 4 ed. São Paulo: Atlas, 2000.

LEVITT, Theodore. A imaginação de marketing. São Paulo: Atlas, 1988.

LUCCHESE, Soraia Maria; RIBEIRO, Núbia Braga. Comportamento do consumidor: aspectos culturais. Minas Gerais, 2012. Dissertação (Graduação em Administração) - Departamento de Administração: Faculdade Padre Machado.

MIGUELES, Carmen (org.). Antropologia do consumo: Casos brasileiros. Rio de Janeiro: Editora FGV, 2007

NÓBREGA, Maílson da. IPCA de setembro sinaliza inflação de 3,5\% em 2019. VEJA, Rio de Janeiro, 09 de outubro de 2019 Disponível em: 
<https://veja.abril.com.br/blog/mailson-da-nobrega/ipca-de-setembro-sinalizainflacao-de-35-em-2019/>. Acesso em: 02 de novembro de 2019

ORNSTEIN, S.; BRUNA, G.; ROMÈRO, M. Ambiente construído \& comportamento: a avaliação pós-ocupação e a qualidade ambiental. São Paulo: Nobel FAUUSP, 1995.

PARENTE, Juracy. Varejo no Brasil: gestão e estratégia. São Paulo: Atlas, 2000.

RUSSEL, James A.; MEHRABIAN, Albert. Environmental variables in costumer research. Journal of Costumer Research, p. 62-63, 1976.

SAATY, Thomas L. Fundamentals of Decision Making and Priority Theory With the Analytic Hierarchy Process. Pittsburgh: RWS Publications, 2000.

SAATY, Thomas L.; VARGAS, Luis G. Models, Methods, Concepts \& Applications of the Analytic Hierarchy Process. Pittsburgh: Kluwer Academic Publishers, 2001.

SHETH, N. Jagdish; MITTAL, Banwari; NEWMAN, I. Bruce. Comportamento do cliente: indo além do comportamento do consumidor. São Paulo: Atlas, 2001.

SHERMAN, E; MATHUR, A; SMITH, R. B. Store environment and consumer purchase behavior: mediating role of consumer emotions. Nova Jersey: John Wiley \& Sons,Inc., 1997.

SHOSTACK, Lynn G. Breaking Free from Product Marketing. Journal of Marketing 41, pp. 73-80. 73-80, 1977

SILVA NETO, Lauro de Araújo; TAGLIAVINI, Massimo. Opções do tradicional ao exótico. 2 ed. São Paulo: Atlas, 2006.

SOBRAL, Filipe; PECI, Alketa. Administração: teoria e prática no contexto brasileiro. São Paulo: Pearson Prentice Hall, 2008. 
SOLOMON, Michael. O Comportamento do Consumidor: comprando, possuindo e sendo. 11 ed. Porto Alegre: Bookman, 2016.

ZEITHAML, Valarie A.; BITNER, Mary Jo; GREMLER, Dwayne D. Marketing de Serviços: A Empresa com Foco no Cliente. 6 ed. Porto Alegre: Bookman, 2014.

ZORRILLA, Pilar. Nuevas tendencias en merchandising: generar experiencias para conquistar emociones y fidelizar clientes. Distribución y Consumo, p. 13-20, 2002. 
APÊNDICE A - IMAGENS UTILIZADAS NA PESQUISA

EXTERNAS -

Esquina:

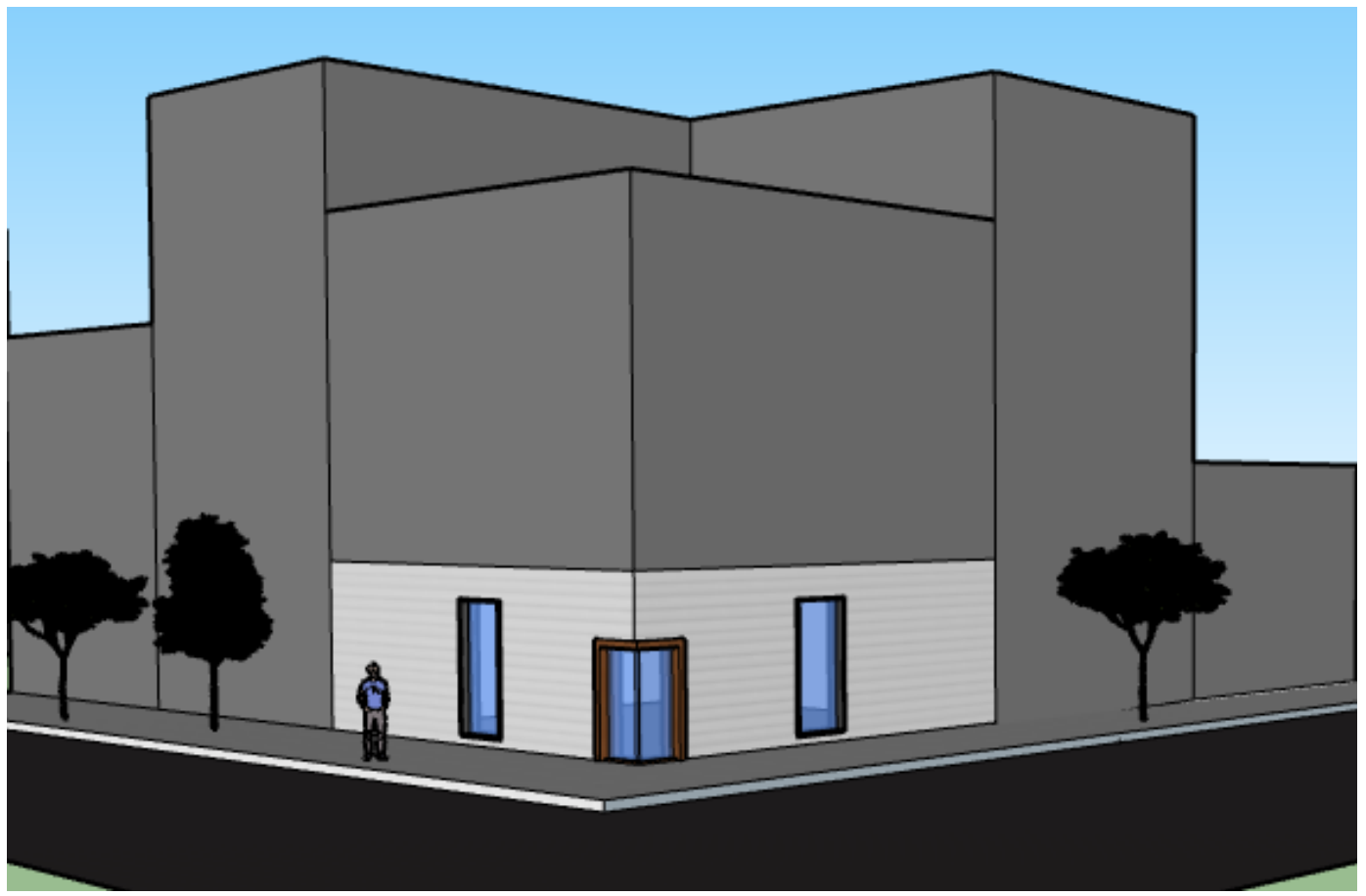

Recuo:

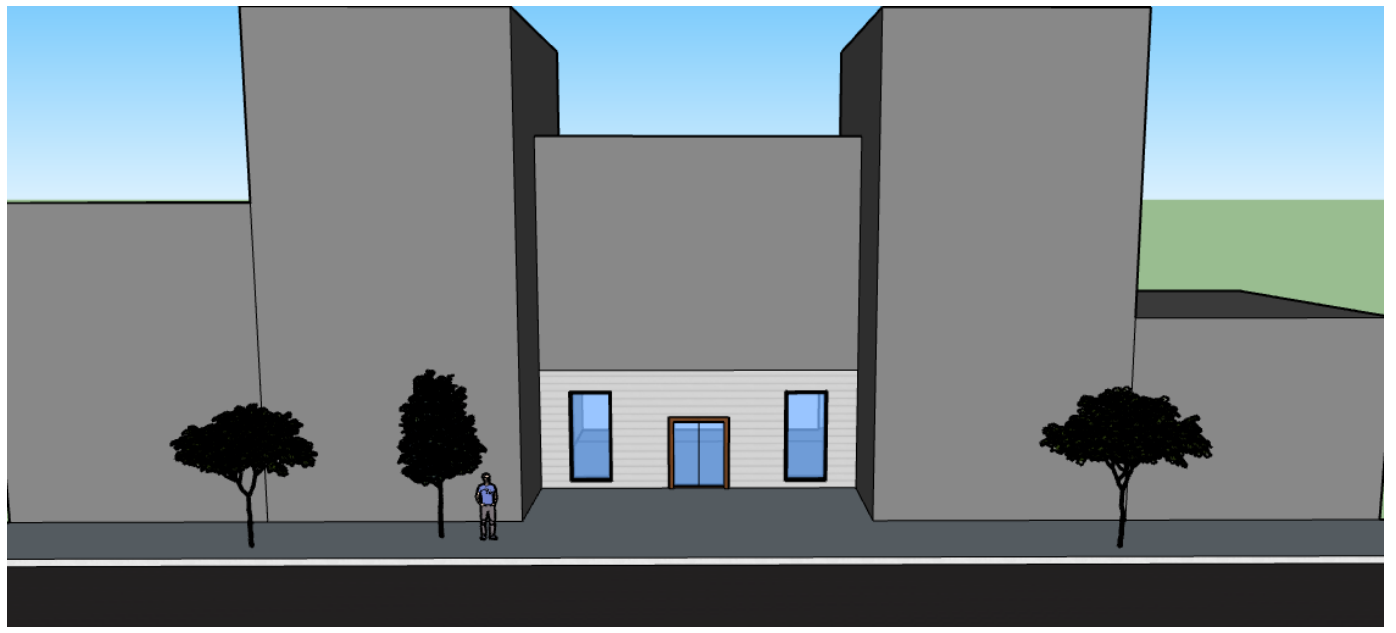


Testada:

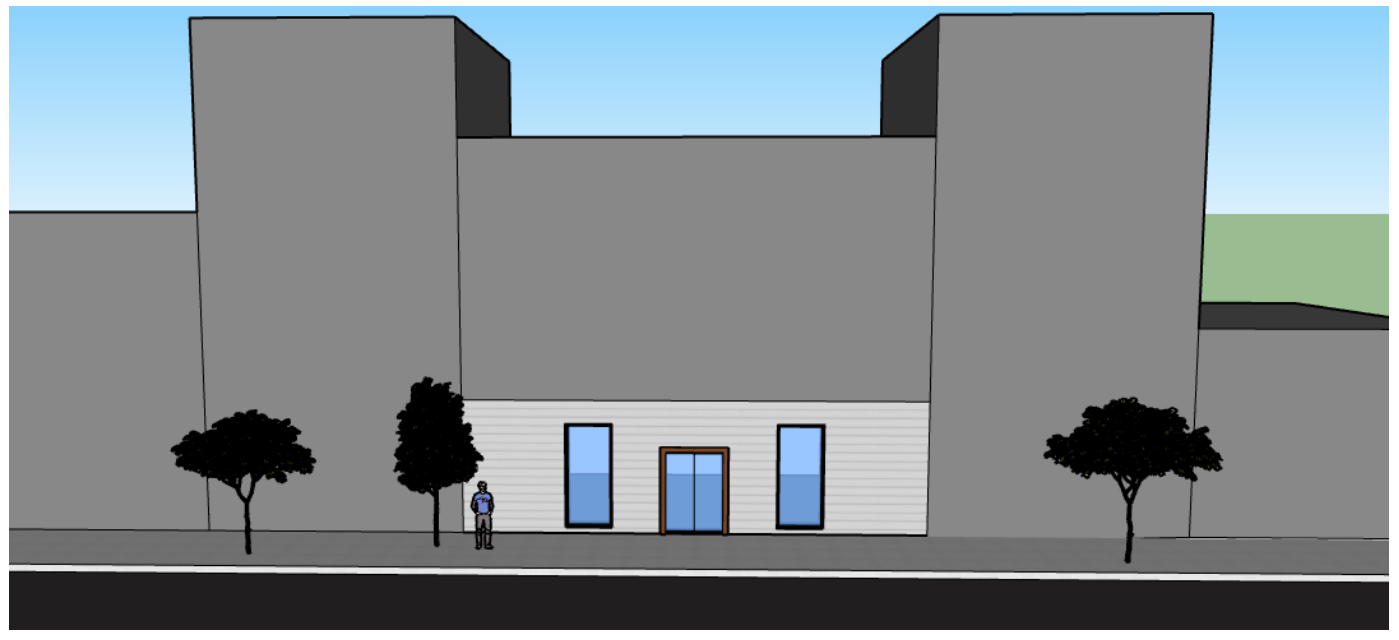

Transparência:

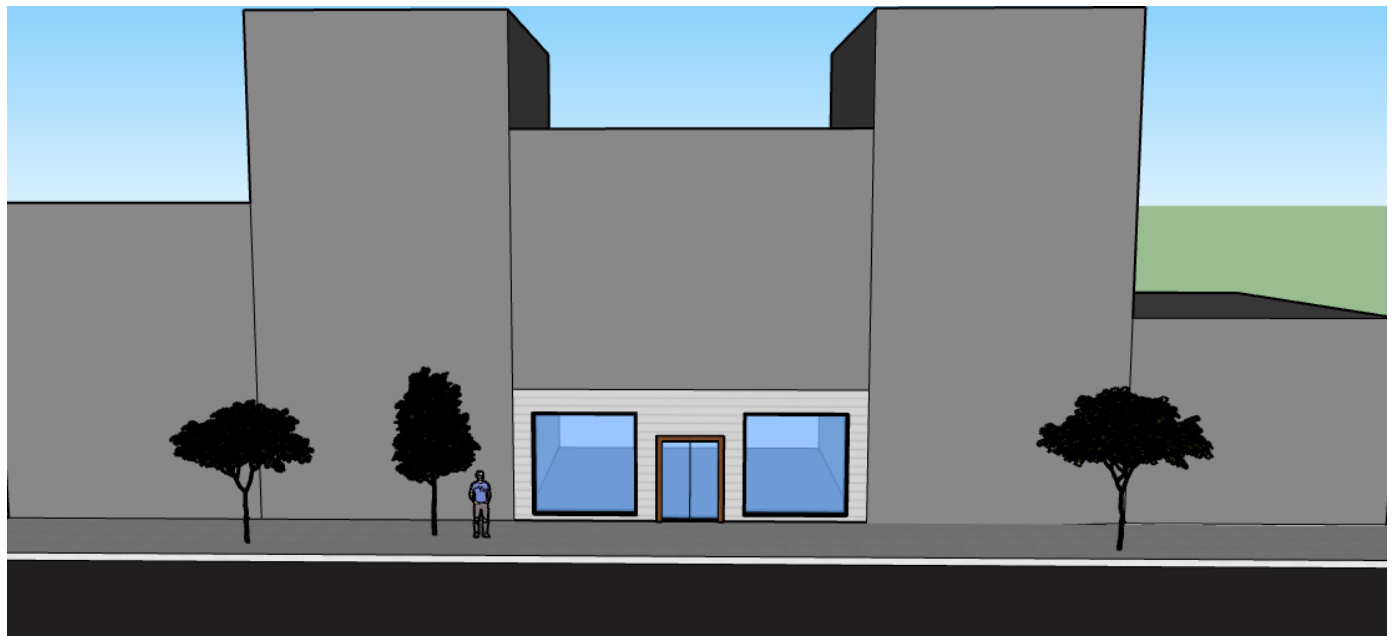


INTERNAS -

Conservação:

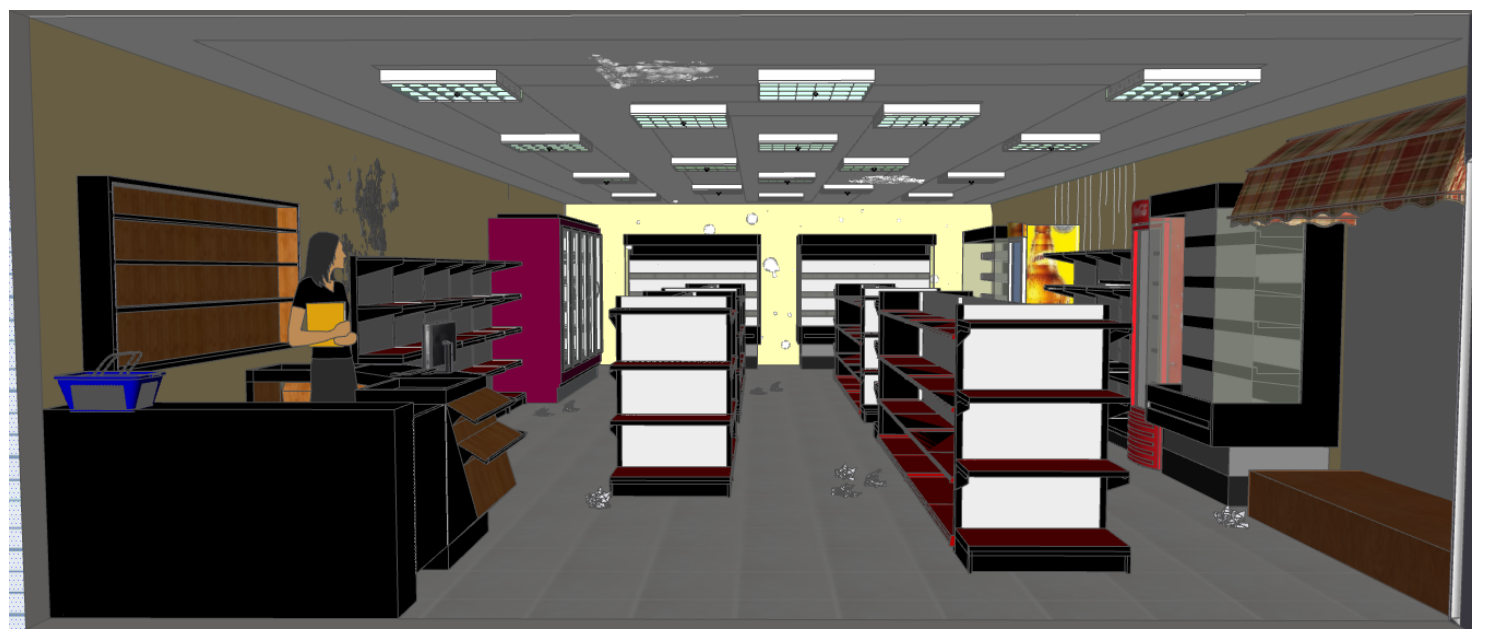

Cores:

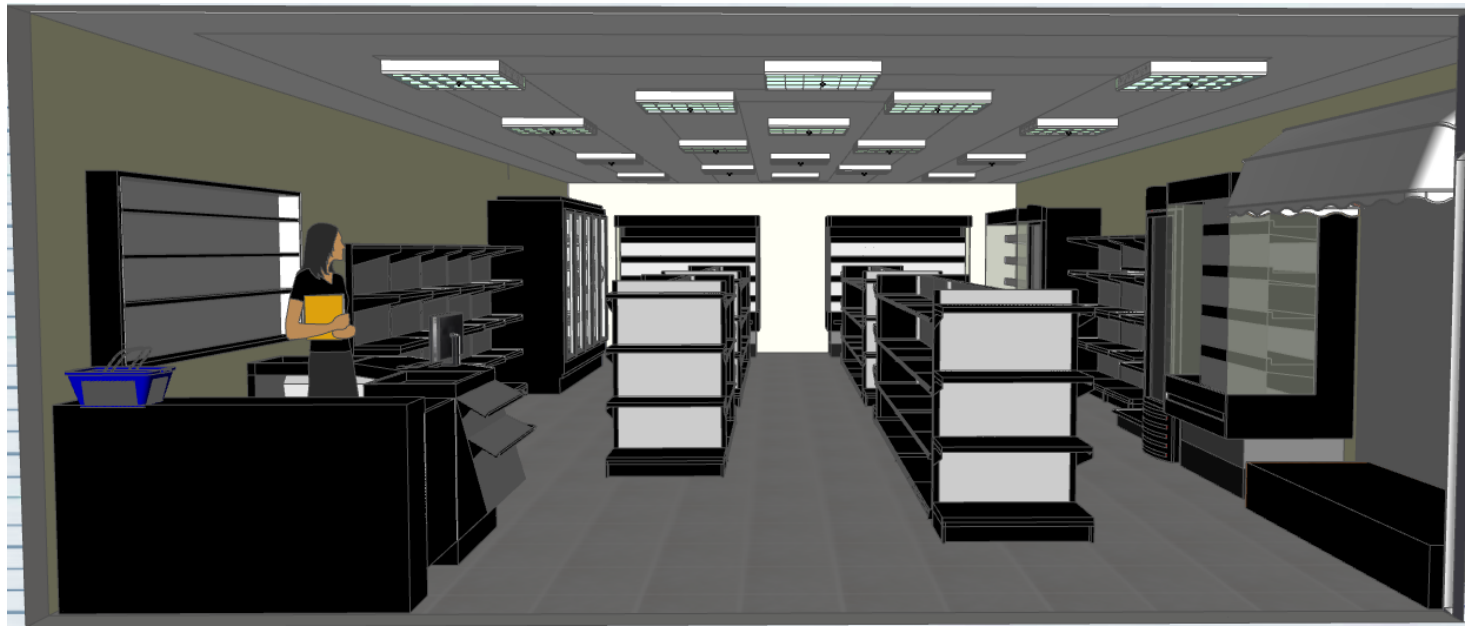


lluminação:

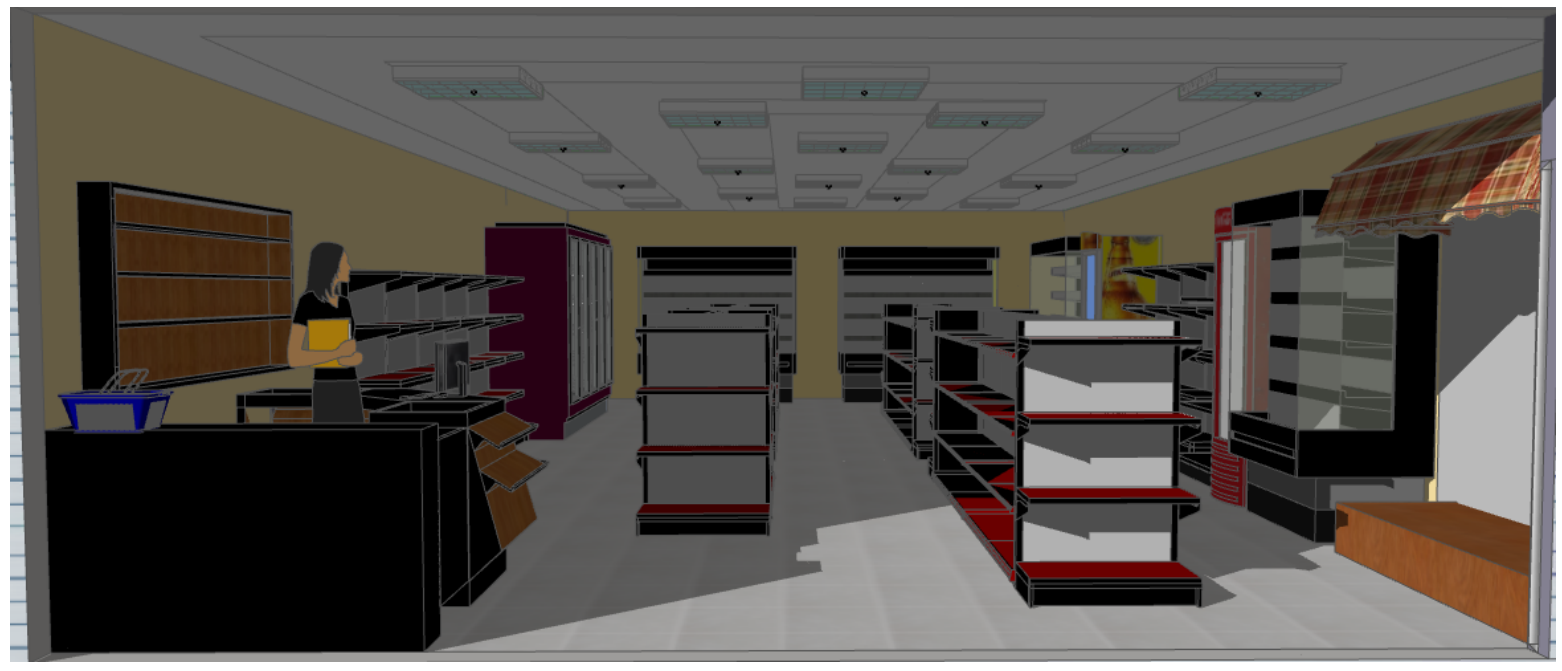

Circulação:

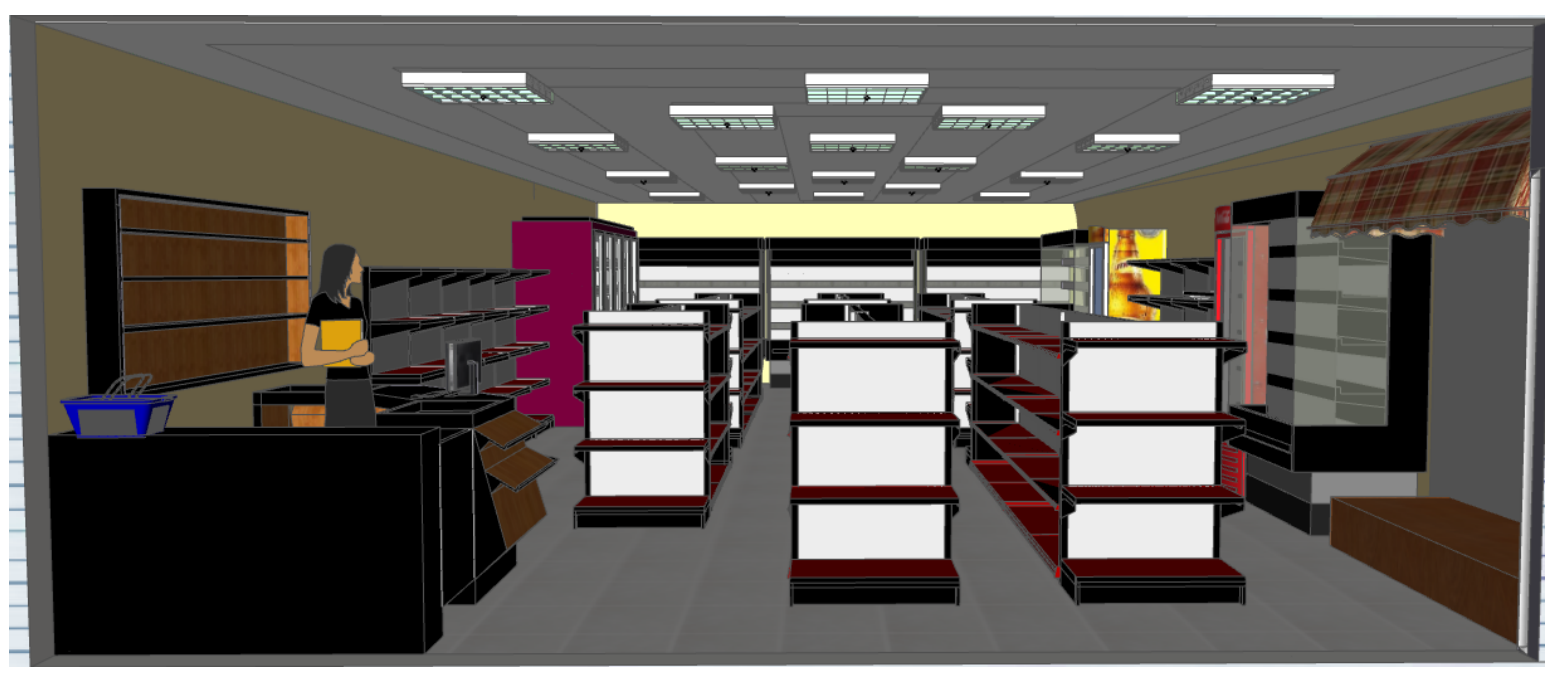




\section{APÊNDICE B - MEMÓRIA DE CÁLCULO}

\section{MATRIZES COMPARAÇÃO CONSUMIDORES -}

Matriz comparação externa/interna:

\begin{tabular}{|c|c|c|}
\cline { 2 - 3 } Objetivo & Externos & Internos \\
\hline Externos & 1 & $1 / 2$ \\
\hline Internos & 2 & 1 \\
\hline
\end{tabular}

Matriz comparação critérios externos:

\begin{tabular}{|c|c|c|c|}
\cline { 2 - 4 } \multicolumn{1}{c|}{ Externos } & Estética & Visibilidade & Conforto \\
\hline Estética & 1 & $1 / 5$ & 7 \\
\hline Visibilidade & 5 & 1 & 9 \\
\hline Conforto & $1 / 7$ & $1 / 9$ & 1 \\
\hline
\end{tabular}

Matriz comparação critérios internos:

\begin{tabular}{|c|c|c|c|}
\cline { 2 - 4 } \multicolumn{1}{c|}{ Internos } & Estética & Visibilidade & Conforto \\
\hline Estética & 1 & 3 & 3 \\
\hline Visibilidade & $1 / 3$ & 1 & $1 / 3$ \\
\hline Conforto & $1 / 3$ & 3 & 1 \\
\hline
\end{tabular}

Matriz comparação características externas (Estética):

\begin{tabular}{|c|c|c|c|c|}
\cline { 2 - 5 } \multicolumn{1}{c|}{ Estética } & Esquina & Recuo & Testada & Transparência \\
\hline Esquina & 1 & $1 / 6$ & $1 / 7$ & $1 / 9$ \\
\hline Recuo & 6 & 1 & $1 / 3$ & $1 / 7$ \\
\hline Testada & 7 & 3 & 1 & $1 / 3$ \\
\hline Transparência & 9 & 7 & 3 & 1 \\
\hline
\end{tabular}

Matriz comparação características externas (Visibilidade):

\begin{tabular}{|c|c|c|c|c|}
\cline { 2 - 5 } \multicolumn{1}{c|}{ Visibilidade } & Esquina & Recuo & Testada & Transparência \\
\hline Esquina & 1 & 9 & 7 & 1 \\
\hline Recuo & $1 / 9$ & 1 & $1 / 7$ & $1 / 9$ \\
\hline Testada & $1 / 7$ & 7 & 1 & $1 / 2$ \\
\hline Transparência & 1 & 9 & 2 & 1 \\
\hline
\end{tabular}


Matriz comparação características externas (Conforto):

\begin{tabular}{|c|c|c|c|c|}
\cline { 2 - 5 } \multicolumn{1}{c|}{ Conforto } & Esquina & Recuo & Testada & Transparência \\
\hline Esquina & 1 & $1 / 3$ & $1 / 3$ & 3 \\
\hline Recuo & 3 & 1 & $1 / 3$ & 3 \\
\hline Testada & 3 & 3 & 1 & 1 \\
\hline Transparência & $1 / 3$ & $1 / 3$ & 1 & 1 \\
\hline
\end{tabular}

Matriz comparação características internas (Estética):

\begin{tabular}{|c|c|c|c|c|}
\cline { 2 - 5 } \multicolumn{1}{c|}{ Estética } & Conservação & Cores & Iluminação & Circulação \\
\hline Conservação & 1 & 7 & $1 / 3$ & 5 \\
\hline Cores & $1 / 7$ & 1 & $1 / 7$ & 5 \\
\hline Iluminação & 3 & 7 & 1 & 6 \\
\hline Circulação & $1 / 5$ & $1 / 5$ & $1 / 6$ & 1 \\
\hline
\end{tabular}

Matriz comparação características internas (Visibilidade):

\begin{tabular}{|c|c|c|c|c|}
\cline { 2 - 5 } Visibilidade & Conservação & Cores & Iluminação & Circulação \\
\hline Conservação & 1 & $1 / 3$ & $1 / 5$ & 3 \\
\hline Cores & 3 & 1 & $1 / 7$ & 7 \\
\hline Iluminação & 5 & 7 & 1 & 9 \\
\hline Circulação & $1 / 3$ & $1 / 7$ & $1 / 9$ & 1 \\
\hline
\end{tabular}

Matriz comparação características internas (Conforto):

\begin{tabular}{|c|c|c|c|c|}
\cline { 2 - 5 } \multicolumn{1}{c|}{ Conforto } & Conservação & Cores & Iluminação & Circulação \\
\hline Conservação & 1 & 5 & $1 / 2$ & 8 \\
\hline Cores & $1 / 5$ & 1 & $1 / 3$ & $1 / 3$ \\
\hline Iluminação & 2 & 3 & 1 & 2 \\
\hline Circulação & $1 / 8$ & 3 & $1 / 2$ & 1 \\
\hline
\end{tabular}


MATRIZES NORMALIZADAS CONSUMIDORES -

Matriz normalizada externa/interna:

\begin{tabular}{|c|c|c|c|}
\hline Objetivo & Externos & Internos & MÉDIA \\
\hline Externos & 0,3333 & 0,3333 & 0,3333 \\
\hline Internos & 0,6667 & 0,6667 & 0,6667 \\
\hline
\end{tabular}

Matriz normalizada critérios externos:

\begin{tabular}{|c|c|c|c|c}
\cline { 2 - 4 } \multicolumn{1}{c|}{ Externos } & Estética & Visibilidade & Conforto & MÉDIA \\
\hline Estética & 0,1628 & 0,1525 & 0,4118 & 0,2424 \\
\hline Visibilidade & 0,8140 & 0,7627 & 0,5294 & 0,7020 \\
\hline Conforto & 0,0233 & 0,0847 & 0,0588 & 0,0556 \\
\hline SOMA & 1 & 1 & 1 &
\end{tabular}

Matriz normalizada critérios internos:

\begin{tabular}{|c|c|c|c|c|}
\hline Internos & Estética & Visibilidade & Conforto & MÉDIA \\
\hline Estética & 0,6000 & 0,4286 & 0,6923 & 0,5736 \\
\hline Visibilidade & 0,2000 & 0,1429 & 0,0769 & 0,1399 \\
\hline Conforto & 0,2000 & 0,4286 & 0,2308 & 0,2864 \\
\hline
\end{tabular}

Matriz normatizada características externas (Estética):

\begin{tabular}{|c|c|c|c|c|c|}
\cline { 2 - 5 } \multicolumn{1}{c|}{ Estética } & Esquina & Recuo & Testada & Transparência & MÉDIA \\
\hline Esquina & 0,0435 & 0,0149 & 0,0319 & 0,0700 & 0,0401 \\
\hline Recuo & 0,2609 & 0,0896 & 0,0745 & 0,0900 & 0,1287 \\
\hline Testada & 0,3043 & 0,2687 & 0,2234 & 0,2100 & 0,2516 \\
\hline Transparência & 0,3913 & 0,6269 & 0,6702 & 0,6300 & 0,5796 \\
\cline { 1 - 5 } SOMA & 1 & 1 & 1 & 1 &
\end{tabular}

Matriz normatizada características externas (Visibilidade):

\begin{tabular}{|c|c|c|c|c|c|}
\cline { 2 - 5 } \multicolumn{1}{c|}{ Visibilidade } & Esquina & Recuo & Testada & Transparência & MÉDIA \\
\hline Esquina & 0,4437 & 0,3462 & 0,6901 & 0,3830 & 0,4657 \\
\hline Recuo & 0,0493 & 0,0385 & 0,0141 & 0,0426 & 0,0361 \\
\hline Testada & 0,0634 & 0,2692 & 0,0986 & 0,1915 & 0,1557 \\
\hline Transparência & 0,4437 & 0,3462 & 0,1972 & 0,3830 & 0,3425 \\
\cline { 1 - 5 } SOMA & 1 & 1 & 1 & 1 &
\end{tabular}


Matriz normatizada características externas (Conforto):

\begin{tabular}{|c|c|c|c|c|c|}
\cline { 2 - 5 } \multicolumn{1}{c|}{ Conforto } & Esquina & Recuo & Testada & Transparência & MÉDIA \\
\hline Esquina & 0,1364 & 0,0714 & 0,1250 & 0,3750 & 0,1769 \\
\hline Recuo & 0,4091 & 0,2143 & 0,1250 & 0,3750 & 0,2808 \\
\hline Testada & 0,4091 & 0,6429 & 0,3750 & 0,1250 & 0,3880 \\
\hline Transparência & 0,0455 & 0,0714 & 0,3750 & 0,1250 & 0,1542 \\
\cline { 1 - 5 } SOMA & 1 & 1 & 1 & 1 &
\end{tabular}

Matriz normatizada características internas (Estética):

\begin{tabular}{|c|c|c|c|c|c|}
\hline Estética & Conservação & Cores & Iluminação & Circulação & MÉDIA \\
\hline Conservação & 0,2303 & 0,4605 & 0,2029 & 0,2941 & 0,2970 \\
\hline Cores & 0,0329 & 0,0658 & 0,0870 & 0,2941 & 0,1199 \\
\hline Iluminação & 0,6908 & 0,4605 & 0,6087 & 0,3529 & 0,5282 \\
\hline Circulação & 0,0461 & 0,0132 & 0,1014 & 0,0588 & 0,0549 \\
\hline SOMA & $\perp$ & 1 & 1 & & \\
\hline
\end{tabular}

Matriz normatizada características internas (Visibilidade):

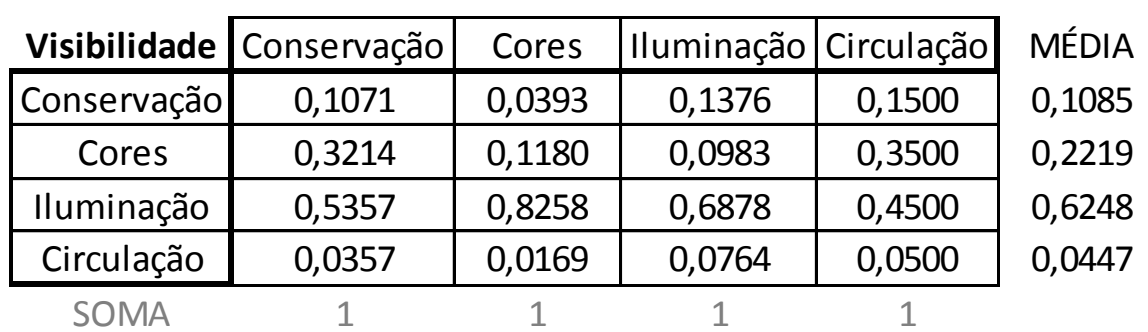

Matriz normatizada características internas (Conforto):

\begin{tabular}{|c|c|c|c|c|c|}
\hline Conforto & Conservação & Cores & Iluminação & Circulação & MÉDIA \\
\hline Conservação & 0,3008 & 0,4167 & 0,2143 & 0,7059 & 0,4094 \\
\hline Cores & 0,0602 & 0,0833 & 0,1429 & 0,0294 & 0,0789 \\
\hline Iluminação & 0,6015 & 0,2500 & 0,4286 & 0,1765 & 0,3641 \\
\hline Circulação & 0,0376 & 0,2500 & 0,2143 & 0,0882 & 0,1475 \\
\hline
\end{tabular}


MATRIZES PRIORIDADE CONSUMIDORES -

Matriz prioridade externa/interna:

\begin{tabular}{|c|c|}
\cline { 2 - 2 } \multicolumn{1}{c|}{} & Objetivo \\
\hline Externos & 0,3333 \\
\hline Internos & 0,6667 \\
\hline
\end{tabular}

Matriz prioridade critérios externos:

\begin{tabular}{|c|c|}
\cline { 2 - 2 } \multicolumn{1}{c|}{} & Externos \\
\hline Estética & 0,2424 \\
\hline Visibilidade & 0,7020 \\
\hline Conforto & 0,0556 \\
\hline
\end{tabular}

Matriz prioridade critérios internos:

\begin{tabular}{|c|c|}
\cline { 2 - 2 } \multicolumn{1}{c|}{} & Internos \\
\hline Estética & 0,5736 \\
\hline Visibilidade & 0,1399 \\
\hline Conforto & 0,2864 \\
\hline
\end{tabular}

Matriz prioridade características externas:

\begin{tabular}{|c|c|c|c|}
\cline { 2 - 4 } \multicolumn{1}{c|}{} & Estética & Visibilidade & Conforto \\
\hline Esquina & 0,0401 & 0,4657 & 0,1769 \\
\hline Recuo & 0,1287 & 0,0361 & 0,2808 \\
\hline Testada & 0,2516 & 0,1557 & 0,3880 \\
\hline Transparência & 0,5796 & 0,3425 & 0,1542 \\
\hline
\end{tabular}

Matriz prioridade características internas:

\begin{tabular}{|c|c|c|c|}
\cline { 2 - 4 } \multicolumn{1}{c|}{} & Estética & Visibilidade & Conforto \\
\hline Conservação & 0,2970 & 0,1085 & 0,4094 \\
\hline Cores & 0,1199 & 0,2219 & 0,0789 \\
\hline Iluminação & 0,5282 & 0,6248 & 0,3641 \\
\hline Circulação & 0,0549 & 0,0447 & 0,1475 \\
\hline
\end{tabular}


MATRIZES COMPARAÇÃO PROFISSIONAIS DE MERCADO -

Matriz comparação externa/interna:

\begin{tabular}{|c|c|c|}
\cline { 2 - 3 } \multicolumn{1}{c|}{ Objetivo } & Externos & Internos \\
\hline Externos & 1 & 2 \\
\hline Internos & $1 / 2$ & 1 \\
\hline
\end{tabular}

Matriz critérios externos:

\begin{tabular}{|c|c|c|c|}
\cline { 2 - 4 } \multicolumn{1}{c|}{ Externos } & Estética & Visibilidade & Conforto \\
\hline Estética & 1 & $1 / 3$ & 3 \\
\hline Visibilidade & 3 & 1 & 5 \\
\hline Conforto & $1 / 3$ & $1 / 5$ & 1 \\
\hline
\end{tabular}

Matriz critérios internos:

\begin{tabular}{|c|c|c|c|}
\cline { 2 - 4 } \multicolumn{1}{c|}{ Internos } & Estética & Visibilidade & Conforto \\
\hline Estética & 1 & 3 & 1 \\
\hline Visibilidade & $1 / 3$ & 1 & $1 / 3$ \\
\hline Conforto & 1 & 3 & 1 \\
\hline
\end{tabular}

Matriz comparação características externas (Estética):

\begin{tabular}{|c|c|c|c|c|}
\cline { 2 - 5 } \multicolumn{1}{c|}{ Estética } & Esquina & Recuo & Testada & Transparência \\
\hline Esquina & 1 & 7 & 3 & 1 \\
\hline Recuo & $1 / 7$ & 1 & $1 / 3$ & $1 / 5$ \\
\hline Testada & $1 / 3$ & 3 & 1 & $1 / 3$ \\
\hline Transparência & 1 & 5 & 3 & 1 \\
\hline
\end{tabular}

Matriz comparação características externas (Visibilidade):

\begin{tabular}{|c|c|c|c|c|}
\cline { 2 - 5 } Visibilidade & Esquina & Recuo & Testada & Transparência \\
\hline Esquina & 1 & 9 & 5 & 7 \\
\hline Recuo & $1 / 9$ & 1 & $1 / 7$ & $1 / 5$ \\
\hline Testada & $1 / 5$ & 7 & 1 & 3 \\
\hline Transparência & $1 / 7$ & 5 & $1 / 3$ & 1 \\
\hline
\end{tabular}

Matriz comparação características externas (Conforto): 


\begin{tabular}{|c|c|c|c|c|}
\cline { 2 - 5 } \multicolumn{1}{c|}{ Conforto } & Esquina & Recuo & Testada & Transparência \\
\hline Esquina & 1 & $1 / 3$ & $1 / 3$ & 3 \\
\hline Recuo & 3 & 1 & 1 & 2 \\
\hline Testada & 3 & 1 & 1 & 3 \\
\hline Transparência & $1 / 3$ & $1 / 2$ & $1 / 3$ & 1 \\
\hline
\end{tabular}

Matriz comparação características internas (Estética):

\begin{tabular}{|c|c|c|c|c|}
\cline { 2 - 5 } \multicolumn{1}{c|}{ Estética } & Conservação & Cores & Iluminação & Circulação \\
\hline Conservação & 1 & 5 & 3 & 5 \\
\hline Cores & $1 / 5$ & 1 & $1 / 3$ & 2 \\
\hline Iluminação & $1 / 3$ & 3 & 1 & 3 \\
\hline Circulação & $1 / 5$ & $1 / 2$ & $1 / 3$ & 1 \\
\hline
\end{tabular}

Matriz comparação características internas (Visibilidade):

\begin{tabular}{|c|c|c|c|c|}
\cline { 2 - 5 } Visibilidade & Conservação & Cores & Iluminação & Circulação \\
\hline Conservação & 1 & $1 / 3$ & $1 / 5$ & 3 \\
\hline Cores & 3 & 1 & $1 / 3$ & 3 \\
\hline Iluminação & 5 & 3 & 1 & 5 \\
\hline Circulação & $1 / 3$ & $1 / 3$ & $1 / 5$ & 1 \\
\hline
\end{tabular}

Matriz comparação características internas (Conforto):

\begin{tabular}{|c|c|c|c|c|}
\cline { 2 - 5 } \multicolumn{1}{c|}{ Conforto } & Conservação & Cores & Iluminação & Circulação \\
\hline Conservação & 1 & 9 & 3 & 3 \\
\hline Cores & $1 / 9$ & 1 & $1 / 6$ & $1 / 7$ \\
\hline Iluminação & $1 / 3$ & 6 & 1 & 1 \\
\hline Circulação & $1 / 3$ & 7 & 1 & 1 \\
\hline
\end{tabular}


MATRIZES NORMATIZADAS PROFISSIONAIS DE MERCADO -

Matriz normalizada externa/interna:

\begin{tabular}{|c|c|c|c|}
\hline Objetivo & Externos & Internos & MÉDIA \\
\hline Externos & 0,6667 & 0,6667 & 0,6667 \\
\hline Internos & 0,3333 & 0,3333 & 0,3333 \\
\hline
\end{tabular}

Matriz normalizada critérios externos:

\begin{tabular}{|c|c|c|c|c}
\cline { 2 - 4 } \multicolumn{1}{c|}{ Externos } & Estética & Visibilidade & Conforto & MÉDIA \\
\hline Estética & 0,2308 & 0,2174 & 0,3333 & 0,2605 \\
\hline Visibilidade & 0,6923 & 0,6522 & 0,5556 & 0,6333 \\
\hline Conforto & 0,0769 & 0,1304 & 0,1111 & 0,1062 \\
\hline SOMA & 1 & 1 & 1 &
\end{tabular}

Matriz normalizada critérios externos:

\begin{tabular}{|c|c|c|c|c}
\cline { 2 - 4 } \multicolumn{1}{c|}{ Internos } & Estética & Visibilidade & Conforto & MÉDIA \\
\hline Estética & 0,4286 & 0,4286 & 0,4286 & 0,4286 \\
\hline Visibilidade & 0,1429 & 0,1429 & 0,1429 & 0,1429 \\
\hline Conforto & 0,4286 & 0,4286 & 0,4286 & 0,4286 \\
\hline SOMA & 1 & 1 & 1 &
\end{tabular}

Matriz normatizada características externas (Estética):

\begin{tabular}{|c|c|c|c|c|c|}
\cline { 2 - 6 } \multicolumn{1}{c|}{ Estética } & Esquina & Recuo & Testada & Transparência & MÉDIA \\
\hline Esquina & 0,4038 & 0,4375 & 0,4091 & 0,3947 & 0,4113 \\
\hline Recuo & 0,0577 & 0,0625 & 0,0455 & 0,0789 & 0,0611 \\
\hline Testada & 0,1346 & 0,1875 & 0,1364 & 0,1316 & 0,1475 \\
\hline Transparência & 0,4038 & 0,3125 & 0,4091 & 0,3947 & 0,380043 \\
\cline { 1 - 5 } SOMA & 1 & 1 & 1 & 1
\end{tabular}

Matriz normatizada características externas (Visibilidade): 


\begin{tabular}{|c|c|c|c|c|c|}
\cline { 2 - 5 } \multicolumn{1}{c|}{ Visibilidade } & Esquina & Recuo & Testada & Transparência & MÉDIA \\
\hline Esquina & 0,6878 & 0,4091 & 0,7721 & 0,6250 & 0,6235 \\
\hline Recuo & 0,0764 & 0,0455 & 0,0221 & 0,0179 & 0,0404 \\
\hline Testada & 0,1376 & 0,3182 & 0,1544 & 0,2679 & 0,219501 \\
\hline Transparência & 0,0983 & 0,2273 & 0,0515 & 0,0893 & 0,116571 \\
\cline { 1 - 5 } SOMA & 1 & 1 & 1 & 1
\end{tabular}

Matriz normatizada características externas (Conforto):

\begin{tabular}{|c|c|c|c|c|c|}
\cline { 2 - 5 } Conforto & Esquina & Recuo & Testada & Transparência & MÉDIA \\
\hline Esquina & 0,1364 & 0,1176 & 0,1250 & 0,3333 & 0,178086 \\
\hline Recuo & 0,4091 & 0,3529 & 0,3750 & 0,2222 & 0,339814 \\
\hline Testada & 0,4091 & 0,3529 & 0,3750 & 0,3333 & 0,367591 \\
\hline Transparência & 0,0455 & 0,1765 & 0,1250 & 0,1111 & 0,114509 \\
\cline { 1 - 5 } SOMA & 1 & 1 & 1 & 1
\end{tabular}

Matriz normatizada características internas (Estética):

\begin{tabular}{|c|c|c|c|c|c|}
\cline { 2 - 5 } \multicolumn{1}{c|}{ Estética } & Conservação & Cores & Iluminação & Circulação & MÉDIA \\
\hline Conservação & 0,5769 & 0,5263 & 0,6429 & 0,4545 & 0,5502 \\
\hline Cores & 0,1154 & 0,1053 & 0,0714 & 0,1818 & 0,1185 \\
\hline Iluminação & 0,1923 & 0,3158 & 0,2143 & 0,2727 & 0,2488 \\
\hline Circulação & 0,1154 & 0,0526 & 0,0714 & 0,0909 & 0,082588 \\
\cline { 1 - 5 } SOMA & 1 & 1 & 1 & 1
\end{tabular}

Matriz normatizada características internas (Visibilidade):

\begin{tabular}{|c|c|c|c|c|c|}
\cline { 2 - 6 } Visibilidade & Conservação & Cores & Iluminação & Circulação & MÉDIA \\
\hline Conservação & 0,1071 & 0,0714 & 0,1154 & 0,2500 & 0,1360 \\
\hline Cores & 0,3214 & 0,2143 & 0,1923 & 0,2500 & 0,2445 \\
\hline Iluminação & 0,5357 & 0,6429 & 0,5769 & 0,4167 & 0,54304 \\
\hline Circulação & 0,0357 & 0,0714 & 0,1154 & 0,0833 & 0,076465 \\
\cline { 1 - 5 } SOMA & 1 & 1 & 1 & 1
\end{tabular}

Matriz normatizada características internas (Conforto):

\begin{tabular}{|c|c|c|c|c|c|}
\cline { 2 - 5 } \multicolumn{1}{c|}{ Conforto } & Conservação & Cores & Iluminação & Circulaçãon & MÉDIA \\
\hline Conservação & 0,5625 & 0,3913 & 0,5806 & 0,5833 & 0,529446 \\
\hline Cores & 0,0625 & 0,0435 & 0,0323 & 0,0278 & 0,041504 \\
\hline Iluminação & 0,1875 & 0,2609 & 0,1935 & 0,1944 & 0,209091 \\
\hline Circulação & 0,1875 & 0,3043 & 0,1935 & 0,1944 & 0,21996 \\
\cline { 1 - 5 } SOMA & 1 & 1 & 1 & 1 &
\end{tabular}


MATRIZES NORMATIZADAS PROFISSIONAIS DE MERCADO -

Matriz prioridade externa/interna:

\begin{tabular}{|c|c|}
\cline { 2 - 2 } \multicolumn{1}{c|}{} & Objetivo \\
\hline Externos & 0,6667 \\
\hline Internos & 0,3333 \\
\hline
\end{tabular}

Matriz prioridade critérios externos:

\begin{tabular}{|c|c|}
\cline { 2 - 2 } \multicolumn{1}{c|}{} & Externos \\
\hline Estética & 0,2605 \\
\hline Visibilidade & 0,6333 \\
\hline Conforto & 0,1062 \\
\hline
\end{tabular}

Matriz prioridade critérios externos:

\begin{tabular}{|c|c|}
\cline { 2 - 2 } \multicolumn{1}{c|}{} & Internos \\
\hline Estética & 0,4286 \\
\hline Visibilidade & 0,1429 \\
\hline Conforto & 0,4286 \\
\hline
\end{tabular}

Matriz prioridade características externas:

\begin{tabular}{|c|c|c|c|}
\cline { 2 - 4 } \multicolumn{1}{c|}{} & Estética & Visibilidade & Conforto \\
\hline Esquina & 0,4113 & 0,6235 & 0,1781 \\
\hline Recuo & 0,0611 & 0,0404 & 0,3398 \\
\hline Testada & 0,1475 & 0,2195 & 0,3676 \\
\hline Transparência & 0,3800 & 0,1166 & 0,1145 \\
\hline
\end{tabular}

Matriz prioridade características internas: 


\begin{tabular}{|c|c|c|c|}
\cline { 2 - 4 } \multicolumn{1}{c|}{} & Estética & Visibilidade & Conforto \\
\hline Conservação & 0,5502 & 0,1360 & 0,5294 \\
\hline Cores & 0,1185 & 0,2445 & 0,0415 \\
\hline Iluminação & 0,2488 & 0,5430 & 0,2091 \\
\hline Circulação & 0,0826 & 0,0765 & 0,2200 \\
\hline
\end{tabular}

